\title{
:econ
}

Instituto de Economía

Facultad de Ciencias Económicas y de Administración

Universidad de la República - Uruguay

Transfer Program Enforcement and Children's Time Allocation

\section{Rodrigo Ceni}

Gonzalo Salas

ISSN: 1510-9305

ISSN: $\quad 1688-5090$ (en papel) (en línea) 
We are grateful for very helpful comments by Russell Cooper, Jerome Adda, Marco Manacorda, Giovanni Pica, Geraint Johnes, Jill Johnes, Andrea Vigorito, Rodrigo Arim, Tommaso Oliviero and Annalisa Sconamiglio.

Forma de citación sugerida para este documento: Ceni, R., y Salas, G. (2019) "Transfer Program Enforcement and Children's Time Allocation”. Serie Documentos de Trabajo, DT 17/2019. Instituto de Economía, Facultad de Ciencias Económicas y Administración, Universidad de la República, Uruguay. 
Transfer Program Enforcement and Children's Time Allocation

Rodrigo Ceni

Gonzalo Salas*

\begin{abstract}
We estimate the enforcement level of conditionalities of two transfer programs and how they affect teenagers' time use, in particular, their school attendance, labor supply, and home production. We develop a structural discrete choice model in which young individuals and their parents decide how to allocate their time, including the decision of whether to attend school. They also choose how many hours to work in the market, time in home production, and leisure. To estimate the model, we use household panel data which combines administrative records and surveys covering the period of 2005-2012 in Uruguay, during which two consecutive CCT programs were introduced with different designs. Our model captures not only the share of individuals who are in fact in studies, working and those who neither study nor work, but also the share and the number of hours in market work and home production, and the GPA distribution. The policy experiments performed indicate that school attendance can be increased by raising the level of enforcement and by changing who in the household receives the cash transfer from the parents to the teenagers.
\end{abstract}

Palabras clave: Time Use; Enforcement; Discrete Choice Models; Conditional Cash Transfer Código JEL: D15, H53, I38, J22

\title{
Resumen
}

En este trabajo estimamos el nivel de enforcement de las condicionalidades de dos programas de transferencias y como afectan el uso del tiempo de los adolescentes, en particular, la asistencia a centros educativos, la oferta laboral, y las actividades domésticas. Desarrollamos un modelo estructural de elección discreta en la cual los adolescentes y sus padres eligen como asignar su tiempo, incluyendo la decisión de asistir a un centro educativo. También eligen las horas que dedican a trabajar, al ocio, y a las actividades domésticas. Para estimar el modelo usamos datos de un panel de hogares, el cual es combinado con registros administrativos y encuestas, que cubren el período 2005-2012 en Uruguay, cuando fueron introducidos dos programas CCT con diferente diseño. El modelo captura no solo la proporción de individuos que trabajan, estudian, o no hacen ninguna de las dos cosas, sino también las horas que dedican al trabajo y a las actividades domésticas, y la distribución del GPA. Los experimentos de política realizados indican que la asistencia a centros educativos podría incrementarse si el nivel de enforcement fuese mayor y si cambiara quien recibe la transferencia de ingreso, los padres o los adolescentes.

Palabras clave: uso del tiempo; enforcement; modelos de elección discreta; Transferencias condicionadas de ingresos

Código JEL: D15, H53, I38, J22

•R. Ceni: IECON, FCEA Universidad de la Republica, Uruguay, email: rceni@iecon.ccee.edu.uy. G. Salas: IECON, FCEA Universidad de la Republica, Uruguay, email: gsalas@iecon.ccee.edu.uy 


\section{Transfer Program Enforcement and Children's Time Allocation}

\section{Introduction}

Research on public economics has traditionally examined the effects of social welfare programs on incentives in labor supply, school attendance and home production, with emphasis on financial constraints that affect individual behavior and the role of the conditionalities in the decision process. Over the last decade, there has been an increasing number of papers that analyze how enforcement impacts these decisions. This paper aims to estimate the level of enforcement relating to middle and high school attendance for two conditional cash transfers $(\mathrm{CCT})$ programs and analyze how this variable affects time use of teenagers in treated families. We develop a structural discrete choice model, where the teenagers and their parents jointly make the decisions about teenagers' time use. To estimate the model parameters, and especially the enforcement levels, we use data from two programs that were designed and carried out (the second replaced the first one) in Uruguay over about ten years.

Government enforcement has a crucial role in the public economics literature. Traditionally, the decision of its level was set through a cost-benefit problem, such as in the seminal papers of Becker (1968) and the extension of Allingham and Sandmo (1972) for the particular case of tax evasion. Since Alm et al. (2009) introduced enforcement on tax compliance in a lab experiment, a significant body of research has been exploring which enforcement strategies work better and how these strategies generate spillovers on the whole economy, with a focus on taxes (Almeida and Carneiro, 2009; Rincke and Traxler, 2011; Almeida and Carneiro, 2012; Drago et al., 2015; Ulyssea and Ponczek, 2018; Slemrod, 2018) and on social programs (Brollo et al., 2017). Following this literature and also in line with those of social norms, enforcement level involves not only the resources that the government invests to carry out the programs but also individual perceptions about program quality and efficiency, and so related estimation has been an issue in economics literature (Posner, 1997; Benabou and Tirole, 2011; Besley et al., 2015; Acemoglu and Jackson, 2017). The enforcement level estimation is the first and main contribution in this paper, insofar as we are able to do it using a structural model which also allows us explore a series of counterfactual situations.

In this paper, we also contribute theoretically and empirically to the literature in three other respects. The second contribution is how the inclusion of time use in utility formation introduces the decision made by parents and teenagers into the model, and the positive utility for those who neither study nor work, especially from leisure. We propose a dynamic model of sequential decisions under uncertainty, based on the seminal paper of Eckstein and Wolpin (1999). In that paper, they develop and estimate a structural model of the decision of 
whether to work and high school attendance, exploiting the NLSY79 to identify who drops out and when they do so. ${ }^{1}$ They find that those who work at the same time as attending high school have lower school performance. In our paper, we theoretically consider parents and teens as jointly making decisions about how the teenager will allocate their time, and also consider a particular group of teenagers who are at the bottom of the income distribution, a significant share of whom neither study nor work, both of which introduce particular features in our model.

We also introduce skills development into the model as satisfaction that schooling gives to the child and their parents. As in Stinebrickner and Stinebrickner (2014), we estimate the grade point average (GPA) dynamic, and it is one of the channels to understand and quantify the decision between work and schooling. Poor educational performance, i.e., low GPA, has in the past increased the dropout probability Entwisle and Kabbani (2001); Griffin (2002); Christle et al. (2002). In this specific process there are two types of incentives which play a determinant role: i) individual incentives, because poor performances can generate frustration in the individual (Finn, 1989) and can reduce how enjoyable it is to be in school (Stinebrickner and Stinebrickner, 2014); and ii) household incentive through the aspirations of parents, i.e. the child's educational performance builds parents' incentives. Because they perceive bad signals in relation to their offspring's academic achievements, they reduce or stop investing in education (Mumford and Li, 2012). This investment in education can operate either through the time that parents spend with their children in educational activities such as reading or homework, or encouraging their children to do it (Del Boca et al., 2017). As in Bursztyn and Coffman (2012), we consider the time use decisions as a negotiation between generations through a weighted utility function. The decision to participate in the education system depends on both parents' and the teenager's utilities. When the parents' utility is low because of poor educational performance, they can be compensated by more income if their offspring participates in the labor market. In the case of teenagers, their utility depends on leisure time and the time spent in alternative activities (school attendance or work). We assume that the utility from attending school depends not only on the GPA but also on completing the level of school.

The third contribution is the estimation of enforcement parameters, fitting statistical moments related to time use using a novel database, which includes time in home production as a part of the household optimization problem, and the interactions with education, work in the market and leisure. The estimation of this model uses a unique database from administrative records and a set of surveys that enable to follow their entire educational history, time in work in the market and time in home production, at no less than two points in time over seven years covering the two CCT programs. This dataset allows us to model how the families decide the teenagers' school attendance, their participation in the labor market and time spent in home production. In this case, we do not consider parents' time, because evidence suggests that parental investments in their child drops during adolescence (Del Boca et al., 2019, 2013; Heckman and Carneiro, 2003), as the effect of child self-investment increases(Cooper et al., 2006).

Finally, we contribute to the analysis of how the CCT program is designed, the mechanism behind the

${ }^{1}$ The National Longitudinal Survey of Youth 1979. 
enforcement level, the dynamics of entry and exit from the program and who in the household is the direct beneficiary of the cash transfer. Empirically, we work with a deprived group of teenagers whose families applied to receive a CCT, either the National Social Assistance Plan for Social Emergency (Plan de Asistencia Nacional a la Emergencia, hereafter PANES) or for Family Allowance (Asignaciones Familiares hereafter, AFAM). Both have encouragement of school participation as among their objectives, but the enforcement levels of these conditionalities were weak. Beyond the normative discussion in relation to CCTs (Pérez-Muñoz, 2017), the effects of CCT programs on school enrollment and attendance have been studied over the last decade in many developing countries. Through a meta-analysis, García and Saavedra (2017) find that the CCT programs have an overall sizable effect, but it is highly heterogeneous, depending whether primary or secondary school, the amount of the transfer, the frequency and the benchmark. Baird et al. (2013) study the effect on school enrollment, comparing the CCT with the unconditional cash transfer (UCT) programs, and within the former group of programs consider both those with and without enforcement by the respective governmental agency. ${ }^{2}$ They find that both CCTs and UCTs affect enrollment, but there are no statistically significant differences among them. Moreover, across the three groups there is a clear statistical difference between those CCT programs with explicit monitoring, and the UCTs and the CCTs with weak control.

The rationale for CCT programs operates on the basis of the decision to attend school and/or work in the market; here, we propose to expand the set of decisions to include home production and leisure time. These decisions have gained relevance in recent years because the share of teenagers who drop out of school and do not enter the labor market has increased (Attanasio et al., 2010). According to the ILO (2013), in Uruguay, which in this regard is at an intermediate level in Latin America, one in five individuals aged between 14 and 19 neither study nor work, half of whom declare they do not do any specific activity during the day. This figure is even higher among individuals in households in the first quintile (lowest income). ${ }^{3}$

These conditionalities affect time use via two mechanisms. First, directly, because one of the conditions to participate in these programs is related to school attendance. Second, the programs indirectly generate behavioral changes based on a change in incentives, decreasing the household investment required to study or the opportunity cost of studying vis-à-vis labor activities. Todd and Wolpin (2006) analyze the effect of a transfer program, PROGRESA, in Mexico on child schooling and fertility. They develop a dynamic behavioral model where first the parents, and then the teenagers, decide either to work or attend school, as well as fertility behavior in the context of a transfer program. Additionally, they perform some counterfactual policy scenarios and propose a different scheme which leads to better school performance. Attanasio et al. (2010) also use a structural model to evaluate PROGRESA in Mexico. They use a randomized experiment to assess if the program is effective and in which respects it could be improved. Our paper goes one step further: we work with two transfer programs, and we analyze how enforcement plays a role in school participation. Finally, we also

\footnotetext{
${ }^{2}$ They consider the level of conditionalities and their enforcement as ranging from 0 to 6 , with UCT programs unrelated to children or education being attributed zero, and those CCTs having explicit conditions with monitoring and enforcement of the attendance condition attributed six.

${ }^{3}$ See Table 1
} 
include a GPA dynamic in the model.

We estimate the structural model that fits the data well and show the extremely low level of the enforcement in both programs. The strength of these parameters leads to change in the teenagers' time use, especially among those who neither study nor work, toward attending middle or high school. Our hypothesis is that we will find a very low level of enforcement in both programs. Also, if the teenager directly receives the transfer, it causes changes in their time use.

The rest of the paper is organized as follows. Section 2 describes the institutional background. In section 3 we describe the databases and the main descriptive statistics. In section 4 the model is developed. In section 5 we present the main results, in section 6 we perform some policy experiments, and in section 7 we discuss the results and the counterfactual experiments. Finally, section 8 concludes.

\section{Institutional background}

In recent years, the Uruguayan government established two social assistance program: PANES between 2005 and 2007 and after that AFAM starting in 2008. These programs have some similarities and many differences. Both programs target the beneficiaries using a baseline poverty score (in Spanish, Índice de Carencias Críticas, ICC) and the household's per capita formal labor market income. The ICC is a multidimensional index that identifies how vulnerable the household is; those above a threshold are eligible for the program. Both PANES and AFAM target poor households but use different thresholds. PANES targeted the first (poorest) quintile of the population and AFAM is focused on all poor households with children (below age 18). The formal income threshold was applied and fully enforced in both programs, but the amounts are not publicized and so have been of any salience for the citizens.

The main differences are the amount of the transfer and the enforcement mechanism. The transfer in PANES was the same amount for all the households, a lump sum which is around $55 \%$ of the full-time monthly minimum wage. ${ }^{4}$ In comparison, the AFAM transfer is linked to the number of household members and educational achievement. The household receives an amount for the first child which is about $30 \%$ of the minimum wage if attending middle or high school and decreases by $40 \%$ for the next younger child up to a total of five siblings. ${ }^{5}$

The income requirement was monitored in PANES and also is in the AFAM program, but only via formal income which is registered through the employment records Bergolo and Cruces (2014). In other words, all income that the families have from informal work is not taken into account. Around 5\% of the PANES and AFAM beneficiaries exit from the programs because those households' formal income is above the threshold. The enforcement of this requirement is widely known and enters into the decision function of the individual. ${ }^{6}$

The level of enforcement of education and health requirements operates on the basis of individual perceptions that if they do not satisfy the requirement they will lose the transfer. Both are perceived as having weak

\footnotetext{
${ }^{4}$ The amount of the monthly transfer to the household was about 60 US dollars.

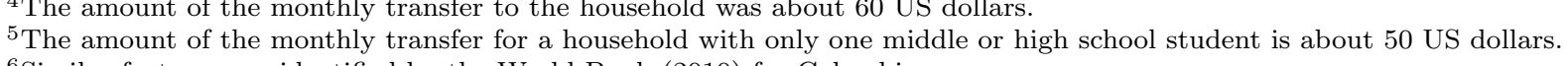

${ }^{6}$ Similar features are identified by the World-Bank (2010) for Colombia.
} 
enforcement. A priori, PANES can be expected to have had higher enforcement than that of AFAM, because the probability of losing the entire transfer depended on any single child. Conversely, in AFAM if one of the children drops out of the education system, the household only loses the part of the transfer that corresponds to that child. However, the enforcement could be expected to be higher in the AFAM case, because when a child starts middle school the family has to present the enrollment certificate in order to receive the $30 \%$ benefit.

We focus only on the period between 2005 and 2012 because of the data available, and because in 2013 the government started to verify the educational requirement twice a year. In April, the government monitors whether the children are enrolled in the educational system, and in September it checks the number of days that they actually attended school in the first months of the school year. This change led to the suspension of some individuals from the program and could have the effect of spilling over to other families through the enforcement perception.

\section{The data and descriptive statistics}

We use data from administrative records and surveys that can be combined using the national ID number of the person. They are: the follow-up survey of PANES (FSP), the follow-up survey for AFAM (FSA) and the middle and high school education record (SER). PANES was a transient program that started in April 2005 and ended in December 2007. The largest component was a lump sum transfer, independent of the number of household members. ${ }^{7}$ The target population of this program was the first quintile (poorest households).

The FSP consists of data collected as part of the evaluation of the PANES program. We have two waves of this survey. The first wave is primarily from 2006, although part of it corresponds to 2007, and the second one corresponds to 2008. In this follow-up survey, it is possible to identify the beneficiaries of the program (treatment group) and those who applied but were not selected (control group) because they are slightly above the threshold. The beneficiary selection criterion was based on the ICC. This survey considers only the population near to the cutoff that identifies the treated and control groups.

The AFAM transfer depends on the number of children in the household and the educational level. The amount for children depends on whether they are in middle or high school and the birth order in the household.

In the same fashion as the FSP, the FSA is an instrument used to evaluate the AFAM program. In this case, we have only one wave, in 2011. The criteria allow us to identify the treated and control populations similarly to the FSP, using the ICC and the formal per capita income threshold. To complement the FSP and FSA data, they are combined with information from the SER, which contains data on the educational performance, in this case the GPA, of students in secondary education. Middle school starts at 12 years of age, after 6 years of primary education, and lasts three years. After that, there are three years of high school, all of which are compulsory. Additionally, we estimate time in home production via the Time Use Survey carried out in 2008 by the National Statistics Institute.

\footnotetext{
${ }^{7}$ In addition, households with children received a food card (in-kind transfer) where the amount depended on the number of children in the household.
} 
In Table 2, we show the mean and standard deviation of the main variables during the respective periods of each CCT program. In the first panel, the data about PANES can be observed. We have 3090 observations of 12 to 18 -year-old individuals. In this sample $75 \%$ attended school. However, only $56 \%$ attended middle school (1716 observations) and 44\% attended high school (1362 observations). Of these cases, we can only locate 707 students in the SER due to the absence of an ID. We do not observe statistically significant changes in the distribution of variables as resulting from the missing cases. In our sample, $70 \%$ of the population was treated, nearly $65 \%$ did home production and $6 \%$ were working. Specific information about educational performance shows that $35 \%$ fail the year of study (obtain an F) and only $20 \%$ obtained a GPA of A. Finally, less than $9 \%$ attended the last years of high school.

In the second panel we show data relating to the AFAM. In this case, $82 \%$ attended formal education ( 7 points higher than in PANES). We have 2796 individuals between 12 and 18 years of age, and high school records were available for 952 of them. The age and the treated population is similar to PANES. The estimation of home production is also quite similar. However, the AFAM sample works less than the PANES one (3 percentage points less).

We define four states with the combination of studying and working choices. In Table 3 , we present the distribution of hours worked and home production by age. Furthermore, we show the distribution of the states that are of interest to us, which are: teenagers who only study $(s n)$, those who study and work (sw), those who neither study nor work $(n n)$ and those who only work $(n w)$. In this case we observe that the number of teenagers who only study decreases significantly with age, and that there is an increasing trend, by age, of those who neither attend school nor work. Additionally, the percentage of those who study and work remains below $10 \%$. In the case of hours worked we note that it increases with age, as expected. The increase in hours allocated to home production presents an irregular trend. Finally, under AFAM, more teenagers are studying and not working, and this is because of the smaller proportion who neither study nor work.

One of the distinguishing features in this paper is the presence of individuals who neither work nor study. In Table 1, we show the information about those teenagers who declare neither studying nor working in the market. These account for $11 \%$ of individuals in the age group of interest in the sample as a whole, although this is eight times higher in first than in the fifth income quintile.

The distribution of GPA by age and grade level is presented in Table 4. The GPA performance is worse when students attend higher level courses and also at higher ages (controlling for grade level). About $64 \%$ of those older than 16 years of age and $72 \%$ of those enrolled the final two years of secondary school do not pass the grade level. This difference is because many students are enrolled at a lower grade level than corresponds to their age because of having failed a grade one or more times. The percentage with a GPA equivalent to A is the same between grades 7 to $10(20 \%)$, and decreases to only $10 \%$ in the last two grades.

Finally, the transition rates between states in consecutive years are shown in Table 5 . The state sn is more stable than the others, with about one-third of the population only studying and remaining in that state in the following year. In all other cases, the proportion of the population remaining in the same state is above $10 \%$. 
Of those $s w$ in $t-1$, in the next year about $60 \%$ stop working and continue studying; this percentage is $28 \%$ and $43 \%$ for the cases of $n n$ and $s w$, respectively.

\section{Model}

We develop a dynamic model of sequential decisions under uncertainty which is based on the basic model of the seminal paper of Eckstein and Wolpin (1999). We consider the share of household utility which depends on the time allocation of the teenager: whether attending school, producing at home, working in the market or enjoying leisure. Additionally, that allocation determines if the household receives (or continues to receive) the CCT. Here we account for the utility that the teenager brings to the household by weighting the utility that the teenager directly enjoys $\left(U_{c h}\right)$, and the utility that the parents $\left(U_{p}\right)$ enjoy through the teenager's time allocation. (Del Boca et al., 2019)

The weight $\left(\gamma_{t}\right)$ depends on the age of the teenager. If the age is below 14 the parent's weight is relatively higher than when they are over 14. The teenager values school attendance, market work and leisure time (residual time after other activities). The parents value school attendance, market work and home production.

$$
U_{t}=\gamma_{t} U_{c h, t}+\left(1-\gamma_{t}\right) U_{p, t}
$$

This utility function could be thought of as the result of a bargaining process between a teenager and parents about the teenager's time allocation where the bargaining power changes with the teenager's age. In the literature of family economics this formalization is used in the decision making of couples (Browning et al., 2014), not of teenagers. The decision is how to split the time between school attendance, home production, leisure, and also market work after they are legally allowed to work.

Given the total hours available of $L_{1}\left(73\right.$ hours per week $\left.{ }^{8}\right)$ for those who attend school, and $L_{2}$ (98 hours per week $^{9}$ ) for those who do not attend school, the rewards in each situation $k=\{s n, s w, n n, n w\}$ depend on the value of attending school $\left(b^{s}\right)$, the value of leisure $\left(b^{n}\right)$, the value of working in the market $\left(\omega h^{w}\right)$ and the value of home production $\left(b^{h p} h^{h p}\right)$. The utility is a weighted function of the teenager's and parents' utility function.

The value when the teenager attends school and does not work $\left(U^{s n}\right)$ includes the value of leisure, the value of studying for both teenagers and parents, and the value of home production in the case of the utility of the parents. The value of studying and working $\left(U^{s w}\right)$ includes the rewards of working $\left(\omega h^{w}\right)$, which is split between the teenager and their parents. The value of neither studying nor working $\left(U^{n n}\right)$ includes only leisure and home production. The value of not studying and working includes home production and rewards of working ( $\left.U^{n w}\right)$. Finally, the value of the CCT is included in the parents' utility function, and it is multiplied by the enforcement parameter $\eta$ for teenagers who are not attending formal education. This parameter summarizes the enforcement

\footnotetext{
${ }^{8}$ This computation is the result of considering that they have 14 hours available per day (after considering sleep, food and personal hygiene) minus 25 weekly hours to attend school and study.

${ }^{9}$ This computation is the result of considering that they have 14 hours available per day.
} 
spillover of the program, e.g. the perceived probability of being monitored. The size of the transfer is different in the two programs, and also depends on whether the formal income of the family exceeds a threshold, with a modelled assumption of perfect enforcement.

Teenagers' utility comes from leisure, school attendance and work in the market:

$$
\begin{aligned}
& U_{c h, t}^{s n}==B_{1, t}^{n}\left(L_{1}-h_{t}^{h p}\right)+B_{1, t}^{s} \\
& U_{c h, t}^{s w}=B_{1, t}^{n}\left(L_{1}-h_{t}^{w}-h_{t}^{h p}\right)+B_{1, t}^{s}+\omega_{t} h_{t}^{w} \\
& U_{c h, t}^{n n}=B_{1, t}^{n}\left(L_{2}-h_{t}^{h p}\right) \\
& U_{c h, t}^{n w}=B_{1, t}^{n}\left(L_{2}-h_{t}^{w}-h_{t}^{h p}\right)+\omega_{t} h_{t}^{w}
\end{aligned}
$$

Parents' utility comes from the teenager's school attendance, time allocated in home production $\left(h_{t}^{h p}\right)$, time working in the market $\left(h_{t}^{w}\right)$ and the $\operatorname{CCT}\left(T_{t}\right)$ :

$$
\begin{aligned}
& U_{p, t}^{s n}=B_{2, t}^{s}+B^{h p}\left(h_{t}^{h p}\right)++T_{t} \\
& U_{p, t}^{s w}=B_{2, t}^{s}+B^{h p}\left(h_{t}^{h p}\right)+\omega_{t} h_{t}^{w}+T_{t} \\
& U_{p, t}^{n n}=B^{h p}\left(h_{t}^{h p}\right)+(1-\eta) T_{t} \\
& U_{p, t}^{n w}=B^{h p}\left(h_{t}^{h p}\right)+\omega_{t} h_{t}^{w}+(1-\eta) T_{t}
\end{aligned}
$$

The value of leisure for the teenager depends positively on age $(t)$, and it is convex in the hours that they do not spend working in the market, on home production, or in formal education. The value also depends on a set of parameters $\left(b_{1 t}^{n}\right.$ and $\left.b_{2}^{n}\right)$ estimated in the model.

$$
B_{1 t}^{n}(h)=b_{1 t}^{n}\left(h^{n}\right)^{b_{2}^{n}}+b_{1 t}^{n}
$$

Rewards from school are to both the teenager and also the parents, and in both cases the rewards are positively affected by the GPA in the previous period $\left(g p a_{t-1}\right)$ and the level of education achieved $\left(E_{t-1}\right)$. The teenager's utility also depends negatively on the hours spent working in the market $\left(h^{h w}\right)$ and on home production $\left(h^{h p}\right)$. The teenager's and parents' parameters, $b_{1}^{s}$ and $b_{2}^{s}$, are both estimated in the model.

$$
\begin{gathered}
B_{1 t}^{s}=b_{1}^{s}\left(g p a_{t-1}, E_{t-1}, h^{h p}, h^{h w}\right)+\epsilon_{1 t}^{s} \\
B_{2 t}^{s}=b_{2}^{s}\left(g p a_{t-1}, E_{t-1}\right)+\epsilon_{2 t}^{s}
\end{gathered}
$$

The enforcement parameters are $\left(\eta_{\text {PANES }}\right.$ and $\left.\eta_{\text {AFAM }}\right)$, which are estimated in the model and will be the key 
parameters to simulate policies:

$$
\eta \in[0,1] \quad \text { if } \quad \eta= \begin{cases}0 & \text { if no enforcement } \\ 1 & \text { if full enforcement }\end{cases}
$$

The GPA follow an ordered logit process which depends on the age, the lag of GPA, the number of working hours, the home production hours and the CCT ( $X$ in Equation 4). The grades can take three values, A, B and F, the lower of which means that the student fails the course.

$$
\begin{aligned}
& g p a^{*}=X \beta+e \quad e / X \sim N(0,1) \\
& g p a_{t}=F \quad \text { if } \quad g p a^{*}<\nu_{1} \\
& g p a_{t}=B \quad \text { if } \quad \nu_{1}<g p a^{*}<\nu_{2} \\
& g p a_{t}=A \quad \text { if } \quad g p a^{*}>\nu_{2}
\end{aligned}
$$

The CCT can be received by a household where the teenager attends school in the first period. Then, in the following periods the household can continue to receive the CCT which depends on school attendance, changes in income and the government enforcement. The probability of losing the transfer from CCT programs consequent to a formal income shock ${ }^{10}$ is $p_{1}$ if the student is not working, and $p_{2}$ for those who are working. These percentages are estimated in two groups: those who are between 12 and 14, and those between 15 and 17 years old.

$$
\begin{array}{r}
P(C C T=0 / C C T=1, n w)=p_{1}(t) \\
P(C C T=0 / C C T=1, w)=p_{2}(t)
\end{array}
$$

The reward from the home production depends on the parameters $b_{t}^{h p}$ estimated in the model, the age $(t)$ and the hours in home production $\left(h^{h p}\right)$ :

$$
B_{t}^{h p}(h)=b_{1 t}^{h p} * t *\left(h^{h p}\right)^{b_{2}^{h p}}
$$

The wage in each time is determined by the age $(t)$, the school attendance $\left(A t_{t}\right)$, the level of education achieved $\left(C S_{t-1}{ }^{11}, B_{t-1}{ }^{12}\right)$, the time spent in home production $\left(h_{t}^{h p}\right)$ and whether the household receives the CCT transfer. The estimation is done in two steps. In the first step we estimate the probability of working, and in the second step we include the Mills ratio to correct for selection bias.

$$
\ln \omega_{t}=\beta_{0}+\beta_{1}(t)+\beta_{2} A t_{t}+\beta_{3} C S_{t-1}+\beta_{4} B_{t-1}+\beta_{5} h_{t}^{h p}+\beta_{6} C C T+\beta_{7} \text { Mills }+\epsilon_{t}^{w}
$$

\footnotetext{
${ }^{10}$ Note that those teenagers who are working mainly do so in the informal market, so exit from the program due to a formal income shock is generally determined by the working situation of their parents

${ }^{11}$ Middle school

${ }^{12}$ High school
} 
The shock's structure is as follows:

$$
\left(\epsilon_{t}^{s}, \epsilon_{t}^{w}\right) \sim N(\mu, \Sigma) \quad \mu=\left(\mu_{s}, \mu_{w}\right) \quad \Sigma=\left(\begin{array}{cc}
\sigma_{s} & 0 \\
0 & \sigma_{w}
\end{array}\right)
$$

The Bellman equations are shown in Equation 11 for each choice and depend on the vector of states $S_{t}$, which are: $C_{t}$ the present level of study, the yearly work hours $h^{w}$, the hours spent on home production $h^{h p}$, the GPA, the age, the CCT (control or treatment) and the shocks $\left(\epsilon^{s}\right.$ and $\left.\epsilon^{w}\right)$ :

$$
\begin{gathered}
V_{t}\left(S_{t}\right)=\max \mathbb{E}\left[\sum_{\tau=t}^{T} \beta^{\tau-t} \sum_{k} U_{t}^{k} d_{t}^{k} / S_{t}\right] \quad k=\{s n, s w, n n, n w\} \\
S_{t}=\left\{C_{t}, h^{w}, h^{h p}, g p a, t, T, \epsilon_{t}^{\prime} s\right\} \\
V_{t}\left(S_{t}\right)=U_{t}^{k}+\beta \mathbb{E}\left[V_{t+1}\left(S_{t+1}\right) \mid S_{t} d_{t}\right]
\end{gathered}
$$

The value function $t<18$ of the different choices are:

$$
V_{t}\left(S_{t}\right)=\max \left[V_{t}^{s n}\left(S_{t}\right), V_{t}^{s w}\left(S_{t}\right), V_{t}^{n n}\left(S_{t}\right), V_{t}^{n w}\left(S_{t}\right)\right]
$$

As in Attanasio et al. (2010), the value at $t=18$ is $V_{18}\left(S_{18}\right)$ which depends on the educational achievement, with $C S$ as completion of middle school and $B$ as completion of high school. The parameters are estimated in the model:

$$
V_{18}\left(S_{18}\right)=\frac{\alpha_{1}}{1+e^{-\alpha_{2} C S_{18}-\alpha_{3} B_{18}-\alpha_{4} E_{t-1}}}
$$

\section{Results}

In this section, we describe how the model works, the estimation strategy for the set of model parameters and the goodness of fit of the data at the main moments. In the model, the individual can only enter the CCT at two times: at the beginning of PANES (in which case they are in that program for 2 years, and then receive AFAM for a maximum of 4 years) or at the beginning of AFAM (in which case they are in that program for a maximum of 6 years). They can enter at any age between 12 and 17, but the exit is always at 18 years of age. Tables 6,7 and 8 show the age distribution, the educational level and treatment (control) status upon entry into each respective program.

There are differences between treatment and control in the background of the teenagers at the time of entry, both within programs and between programs. In both cases, control teenagers have a better educational background than the treated ones, although AFAM treated individuals have a better background than the PANES ones. Note that the AFAM program is more broadly applied than PANES; on average, the AFAM teenagers have a better socioeconomic situation and better educational background. We can observe in tables 
7 and 8 that the percentage of teens not having completed primary school is 10 points lower in the AFAM population compared to PANES. These differences in educational level and age are the main heterogeneity of the individuals in our model, upon starting to receive benefits.

The estimation strategy has two steps. In the first, we use the model to estimate the wage function, the home production function, the GPA function and transition among states. The second step is the estimation of a group of parameters $\hat{\Omega}_{S, N, W}$ via Simulated Method of Moments (SMM). For each individual $i \in N$ we simulate the model $S$ times, yielding $S x N$ paths. We compare the simulated moments with those in the data, minimizing the distance weighted by the inverse of the simulated variance of the moments $W_{N}$.

$$
\hat{\Omega}_{S, N, W}=\operatorname{argmin}_{\Omega}\left(M_{N}-\tilde{M}_{S}(\Omega)\right)^{\prime} W_{N}\left(M_{N}-\tilde{M}_{S}(\Omega)\right)
$$

Then

$$
p \lim _{N \rightarrow \infty, S \rightarrow \infty} \tilde{\Omega}_{S, N, W}=\Omega
$$

Firstly, in tables 9 - 12 we present the estimated parameters out of the model. We estimate the wage equation (Equation 9) for the teenagers in our sample (Table 9) using the FSP and the FSA. We observe an unexpected negative sign on education, and a positive sign on home production and age. But, in the age range studied and in this context, work experience has a positive impact in the wage equation, whereas education does not. Home production has a positive correlation with wages because there is a complementarity between the intensity in the labor market and the amount of tasks that the teenager does at home.

In Table 10 we can see that time in home production increases with age, if they are female, and if they have offspring. The parameters are negative for education and working in the market.

The GPA dynamics estimated in Equation 4 are shown in Table 11. Performance in $t-1$ has a positive impact on $t$. The probability of increased GPA in $t$ is similar at each age level: people over 14 years of age have similar probability regarding GPA in $t$ when obtaining an $\mathrm{F}$ or $\mathrm{B}$ in $t-1$. Neither the coefficients on time in home production nor in market work are significant.

Finally, we perform a multinomial logit to estimate the transition between states in the model. The results are in Table 12. As is expected, not only is there some stability of states between $t$ and $t-1$, but also there are significant movements between $n n$ and $n w$ (on both sides). Finally, the probability of losing the CCT pursuant to a formal income shock is estimated using the administrative records and, respectively at the ages of 12-14 and $15-17$, setting $p_{1}$ as $5.08 \%$ and $3.97 \%$ and $p_{2}$ as $4.69 \%$ and $5.88 \% .^{13}$

The second step of the estimation is by SMM, minimizing the distance between the simulated moments in the model and those in the data, weighting by the inverse of the simulated variance of the moments. To construct the list of moments we use the treated and control groups. The first is defined as those who receive the CCT in the year of program entrance in the model, and the latter is the others.

The total number of hours that the teenagers have available to spend is 98 hours per week, and if they

\footnotetext{
${ }^{13}$ PANES and AFAM respectively
} 
attend school they spend 25 hours in that activity. ${ }^{14}$ On a yearly basis, therefore, they have 5096 available hours after subtracting 3536 hours. Individuals can choose to do (or not do) some home production for 0 , 6 or 12 hours per week (0,312 and 624 hours per year) and to work (or not) in the market for 0, 10 or 20 hours per week (0, 520 and 1040 hours per year).

The constructed moments are as follows: for both control and treated populations/samples in each program, time spent in home production, time working in the market, GPA and the four states $s n, s w, n n$, and $n w$. The estimated parameters are presented in Tables 13 and 14.

In tables 13 and 14 we show the main parameters of the model. In Table 13 there is the set of parameters which vary with age, such as the utility function weights, the leisure and home production functional forms. As the teenagers became older, their relative weight in the household decision function increases, from less than one-third to more than three-quarters. Leisure values increase with age and exponentially with the number of hours that the teenagers have remaining after the school, home production and labor decision. The reward of home production does not show a monotonic behavior with age due to the set of options to change how they spend their time, and the probability of having offspring rises.

In Table 14 we show a second set of parameters. The school reward parameter is higher for the teenagers than for their parents. The set of enforcement parameters in both programs appears to have been very low, reflecting that households do appear to be aware that school attendance is not monitored by authorities, i.e. that the risk to lose the transfer is negligible. However, the two programs differ on this point. These low levels of enforcement mean that there is room for policymakers to propose means of achieving better results.

The enforcement parameters in the model influence the cash transfers that the parents receive, i.e. the teenagers do not account for this income in their school attendance rewards. This could mean that either they decide to use their time more intensively in other activities such as work in the market or in the home, or leisure, or, if they fail a grade they do not have incentives to continue.

Finally, the total value that the individuals obtain at the age of 18 depends on equation 14 and the set of parameters in Table 14, where $\alpha_{1}$ is the parameter of middle school achievement, $\alpha_{2}$ of high school and $\alpha_{3}$ the parameter related to completion of each grade.

In figures 1 - 8, we present how well the model fits the main moments from the data, when using the parameters estimated above. In the set of figures $1-4$ we show how well the model fits the main activities through the four states $(s n, s w, n n$ and $n w)$ in both programs for treated and control populations. In both programs, the model fits well with the only exception being for control samples where there is an underestimation of $s n$ and an overestimation of $n n$. The initial heterogeneity is that these teenagers have better conditions than the treated ones, and so parametrization cannot perfectly replicate the behavior of control ones (figures 1 and $3)$.

In figures 2 and 4, we include the working situation in the time use and this activity fits the model well. However, when we separately consider those who study and work and those who work but do not

\footnotetext{
${ }^{14}$ The total number of hours in a week is 168 hours. We subtract 70 hours for personal needs.
} 
study, the model has more problems. Those who only work is somewhat overestimated, and those who study and work underestimated. In the model, there are more incentives to only work than to work and study contemporaneously. Comparing the treated and control teenagers, the model captures a slightly higher attendance rate for the treated ones. The construction of the model paths depends on the initial heterogeneity and control individuals have better background than the treated. The rewards are also a little higher than the control ones due to self-selection: the teenagers that attend are the ones who previously obtained higher academic results.

The model also properly fits home production, work and GPA, as is shown in figures 5-8. In the case of home production, the model reveals different results for the teenagers that do less than 10 hours per week and those that do more. The model is able to replicate the trend by age in both time brackets. This trend appears in both time brackets, but in the first there is no clear difference by age, whereas in the second the size of the difference is clearly increasing in age. In the case of number of working hours, the model has poor goodness of fit for hours in market work, because as we mentioned before the model overestimates the more intensive workers, and underestimates the less intensive ones.

Finally, the model effectively captures variation in GPA by age of the teenagers as is shown in Figure 8 . The trend is captured well in terms of decreasing frequency of grades of A and B, and increasing frequency of F. Note that at the age of 12 the percentages are $14.2 \%, 54.0 \%$ and $31.8 \%$ respectively for the GPAs corresponding to $\mathrm{F}, \mathrm{B}$ and $\mathrm{A}$, whereas at the age of 17 these are $57.0 \%, 31.6 \%$ and $11.3 \%$.

\section{Policy experiments}

In this section we perform several policy experiments with the enforcement parameters and who in the household receives the transfer: a) slightly higher enforcement, b) maximum enforcement, c) change in who receives transfer, and then combine the previous, with d) a change in who in the household receives the transfer with a small increase in enforcement, and e) in this case also with maximum enforcement. We measure the effects of the policy experiments in both programs, observing the difference-in-difference between treated and control, and between the policy and benchmark. We find that for any age, the total effect sums to zero because we compute the change of time use of teenagers among the four states described above.

We set first the enforcement parameters $\eta_{\text {PANES }}$ at 0.557 instead at 0.057 , and $\eta_{\text {AFAM }}$ at 0.611 instead at 0.111 (see Figure 9.) Here we consider only the time studying and working in the market ${ }^{15}$ There is a rise in the time use to only study and to study and work, and a fall in all the other states at all the ages. These rises are higher in PANES than AFAM and for the younger ones: recall that the teenagers in the second program have a better background than in the first one.

Secondly, we set the enforcement parameters at the maximum of 1 ( $\eta_{\text {PANES }}$ and $\left.\eta_{\text {AFAM }}\right)$. The results in Figure 10 show the effect on the time spent studying as being much bigger than before. There are about 10 percentage

\footnotetext{
${ }^{15}$ In the Appendix there are the effects of all policy experiments on home production, the amount of hours working in the market and the grades.
} 
points more teenagers who study and do not work. Those teenagers that study more mainly come from among those who neither study nor work in contrast to the preceding case. Here again, the effect is higher in PANES than in AFAM, although in this case it is for ages. These two polices on enforcement parameters also change other aspects of the time use, reducing the home production in the early ages and the amount of hours they work in the market (figures A.1, A.2, A.4, and A.5).

In the third policy, we change the cash transfer beneficiary with the estimated level of enforcement in the benchmark. In Figure 11 there is no a clear pattern of change if the teenagers now receive the transfer, which could be because due to the low level of enforcement there are no clear incentives to behave differently.

Finally, in the fourth and fifth policy experiments we then combine the two of the previous policy experiments: the teenagers receive the transfer, and either a small increase of enforcement or the maximum value of enforcement. The results in Figure 11 and Figure 12 show a change in the time use in favor of study and not working. If the teenagers receive the transfer and there is a small increase in enforcement, there are similar consequences than in the second policy when the level of enforcement was maximum.

\section{Discussion}

The main point of this paper is to estimate the level of enforcement of two transfer programs and time use among teenagers. One of the issues that we have to deal with is the initial heterogeneity of individuals in the model, especially among the control ones. This issue can be observed when matching moments, but does not appear to be relevant in the policy experiments.

The model is effective at capturing the extensive margin of the labor supply, but it has more problems to discern between those who work and study from those who do not, and also the intensity of the work. Most individuals do some home production, but these activities are not fully captured in the model when they spend few hours doing this activity. When we perform policy experiments, the results about the work and home production intensity are not so evident as the other households' decisions.

Note that enforcement perception depends both on the belief of individuals about which is the right thing to do and the level of monitoring in practice. The former point is related to social norms and moral/ethical views about the law whereas the role of the policy is more difficult to determine. The latter point can be related to the probability and the beliefs about being effectively audited, and here there is wide room of action of any policy.

Finally, the policy experiments show that the enforcement policies can be complementary with changes to the transfer beneficiary, both of which policies can lead to more time in school. 


\section{Concluding remarks}

In this paper we develop a dynamic model of teenagers' time use to estimate the level of enforcement of two transfer programs. We exploit the fact that teenagers have to comply with some requirements to qualify for eligibility to receive the CCT. We model not only school attendance, but also work and the home production. Moreover, we model the enforcement of the CCT program, in particular estimating a parameter that shows how the beneficiaries perceive the enforcement level. We exploit a wide, rich and novel dataset combining administrative records and survey data for Uruguay for two CCT programs, in which one of the conditions was school attendance.

In the model, the decision is made by the teenagers and their parents, in consideration of the utility that each decision brings to the household, although the weight of the teenagers in the decision changes over time. This model is effective in capturing the distribution of states of individuals, not only among the school attendance and number of hours in the labor market, but also the time that they spend in home production. A large percentage of teenagers neither study nor work, and this is a challenge for the model. The estimated enforcement level is very low in both programs, which may provide impetus toward policies which may, normatively, increase it toward better behaviors.

We perform five policy experiments to assess the role of the enforcement parameter, and who receives the transfer, in the household decision. When the enforcement is higher the treated teenagers attend formal education more, especially between the ages of 14-17, before which there is little room to improve given the already higher rates. The younger teenagers cannot attend more, but they change their time use as time progresses, spending fewer hours on home production. Those teenagers who are legally able to work do so less and with less intensity. These policy experiments show that if the level of enforcement is moderately higher (50 percentage points higher than in the estimation), the rate of those who study rises by between $4 \%$ and $10 \%$ and if it is maximum (set at 1), the rate of those who study rises by between $9 \%$ and $18 \%$.

The policies which change who receives the transfer impact time use, when we simultaneously increase the level of enforcement. Those impact are similar to when we set the enforcement value to the maximum value, and give some insight to design policies that include both dimensions. 


\section{References}

Acemoglu, D. and Jackson, M. O. (2017). Social Norms and the Enforcement of Laws. Journal of the European Economic Association, 15(2):245-295.

Allingham, M. G. and Sandmo, A. (1972). Income tax evasion: A theoretical analysis. Journal of Public Economics, 1(3-4):323-338.

Alm, J., Jackson, B. R., and McKee, M. (2009). Getting the Word Out: Enforcement Information Dissemination and Compliance Behavior. Journal of Public Economics, 93(3-4):392-402.

Almeida, R. and Carneiro, P. (2009). Enforcement of labor regulation and firm size. Journal of Comparative Economics, 37(1):28-46.

Almeida, R. and Carneiro, P. (2012). Enforcement of Labor Regulation and Informality. American Economic Journal: Applied Economics, 4(3):64-89.

Attanasio, O., Fitzsimons, E., Gomez, A., Gutierrez, M. I., Meghir, C., and Mesnard, A. (2010). Children's Schooling and Work in the Presence of a Conditional Cash Transfer Program in Rural Colombia. Economic Development and Cultural Change, 58(2):181-210.

Baird, S., Ferreira, F., Ozler, B., and Woolcock, M. (2013). Relative effectiveness of conditional and unconditional cash transfers for schooling outcomes in developing countries: A systematic review. Campbell Systematic Reviews 2013:8, The Campbell Collaboration.

Becker, G. S. (1968). Crime and Punishment: An Economic Approach. Journal of Political Economy, 76:169.

Benabou, R. and Tirole, J. (2011). Laws and Norms. NBER Working Papers 17579, National Bureau of Economic Research, Inc.

Bergolo, M. and Cruces, G. (2014). Work and Tax Evasion Incentive Effects of Social Insurance Programs. Journal of Public Economics, 117(C):211-228.

Besley, T. J., Jensen, A., and Persson, T. (2015). Norms, Enforcement, and Tax Evasion. CEPR Discussion Papers 10372, C.E.P.R. Discussion Papers.

Brollo, F., Kaufmann, K. M., and La Ferrara, E. (2017). Learning about the Enforcement of Conditional Welfare Programs: Evidence from Brazil. IZA Discussion Papers 10654, Institute for the Study of Labor (IZA).

Browning, M., Chiappori, P., and Weiss, Y. (2014). Economics of the Family. Cambridge University Press.

Bursztyn, L. and Coffman, L. C. (2012). The Schooling Decision: Family Preferences, Intergenerational Conflict, and Moral Hazard in the Brazilian Favelas. Journal of Political Economy, 120(3):359 - 397.

Christle, C., Jolivette, K., and Nelson, C. (2002). The high school journal. Remedial and Special Education, $85(4): 325-339$.

Cooper, H., Robinson, J. C., and Patall, E. A. (2006). Does homework improve academic achievement? a synthesis of research, 1987-e2003. Review of educational research, 76(1):1-62.

Del Boca, D., Flinn, C., Verriest, E., and Wiswall, M. (2019). Actors in the child development process. Carlo Alberto Notebooks 560, Collegio Carlo Alberto.

Del Boca, D., Flinn, C., and Wiswall, M. (2013). Household Choices and Child Development. The Review of Economic Studies, 81(1):137-185. 
Del Boca, D., Monfardini, C., and Nicoletti, C. (2017). Parental and Child Time Investments and the Cognitive Development of Adolescents. Journal of Labor Economics, 35(2):565-608.

Drago, F., Mengel, F., and Traxler, C. (2015). Compliance Behavior in Networks: Evidence from a Field Experiment. CSEF Working Papers 419, Centre for Studies in Economics and Finance (CSEF), University of Naples, Italy.

Eckstein, Z. and Wolpin, K. I. (1999). Why youths drop out of high school: The impact of preferences, opportunities, and abilities. Econometrica, 67(6):1295-1340.

Entwisle, K. A. D. and Kabbani, N. (2001). The dropout process in life course perspective: Early risk factors at home and school. Teachers College Record, 103:760-823.

Finn, J. (1989). Withdrawing from school. Review of Educational Research, 59(2):117-142.

García, S. and Saavedra, J. E. (2017). Educational impacts and cost-effectiveness of conditional cash transfer programs in developing countries: A meta-analysis. Review of Educational Research, 87(5):921-965.

Griffin, B. (2002). Academic disidentification, race, and high school dropouts. High School Journal, 85(4):71-81.

Heckman, J. and Carneiro, P. (2003). Human Capital Policy. NBER Working Papers 9495, National Bureau of Economic Research, Inc.

ILO (2013). Trabajo decente y juventud en américa latina. 2013. World bank other operational studies, Oficina Regional para América Latina y el Caribe.

Mumford, K. and Li, Y. (2012). Aspirations, expectations and education outcomes for children in britain: Considering relative measures of family efficiency. International Journal of Learning, 18(4):289-308.

Pérez-Muñoz, C. (2017). What is wrong with conditional cash transfer programs? Journal of Social Philosophy, $48(4): 440-460$.

Posner, R. A. (1997). Social norms and the law: An economic approach. American Economic Review, 87(2):36569.

Rincke, J. and Traxler, C. (2011). Enforcement Spillovers. The Review of Economics and Statistics, 93(4):12241234.

Slemrod, J. (2018). Tax compliance and enforcement. Working Paper 24799, National Bureau of Economic Research.

Stinebrickner, R. and Stinebrickner, T. (2014). Academic performance and college dropout: Using longitudinal expectations data to estimate a learning model. Journal of Labor Economics, 32(3):601-644.

Todd, P. E. and Wolpin, K. I. (2006). Assessing the impact of a school subsidy program in mexico: Using a social experiment to validate a dynamic behavioral model of child schooling and fertility. American Economic Review, 96(5):1384-1417.

Ulyssea, G. and Ponczek, V. (2018). Enforcement of Labor Regulation and the Labor Market Effects of Trade: Evidence from Brazil. IZA Discussion Papers 11783, Institute for the Study of Labor (IZA).

World-Bank (2010). Informality in colombia : Implications for worker welfare and firm productivity. World Bank Other Operational Studies 2889, The World Bank.

\section{Tables}


Table 1: Characteristics of Young People (Neither Working Nor Studying) in Uruguay

\begin{tabular}{lccccc}
\hline \hline & & \multicolumn{3}{c}{ Main activity } & \\
\cline { 3 - 5 } & Incidence & $\begin{array}{c}\text { Unemploy- } \\
\text { ment }\end{array}$ & $\begin{array}{c}\text { Home } \\
\text { production }\end{array}$ & $\begin{array}{c}\text { Other } \\
\text { activities }\end{array}$ & Total \\
\hline Overall & $17 \%$ & $37 \%$ & $33 \%$ & $30 \%$ & $100 \%$ \\
Male & $13 \%$ & $48 \%$ & $7 \%$ & $45 \%$ & $100 \%$ \\
$14-17$ years old & $12 \%$ & $17 \%$ & $10 \%$ & $73 \%$ & $100 \%$ \\
$18-24$ years old & $16 \%$ & $59 \%$ & $5 \%$ & $36 \%$ & $100 \%$ \\
$25-29$ years old & $9 \%$ & $58 \%$ & $8 \%$ & $34 \%$ & $100 \%$ \\
Female & $21 \%$ & $30 \%$ & $49 \%$ & $21 \%$ & $100 \%$ \\
$14-17$ years old & $11 \%$ & $9 \%$ & $37 \%$ & $54 \%$ & $100 \%$ \\
$18-24$ years old & $26 \%$ & $35 \%$ & $46 \%$ & $19 \%$ & $100 \%$ \\
$25-29$ years old & $23 \%$ & $30 \%$ & $59 \%$ & $11 \%$ & $100 \%$ \\
Income per capita & & & & & \\
First quintile & $31 \%$ & $34 \%$ & $36 \%$ & $30 \%$ & $100 \%$ \\
Fifth quintile & $4 \%$ & $47 \%$ & $15 \%$ & $38 \%$ & $100 \%$ \\
\hline Source: 2015 Household Survey & & & &
\end{tabular}

Table 2: Descriptive Statistics

\begin{tabular}{|c|c|c|c|c|c|c|c|c|c|}
\hline & \multicolumn{3}{|c|}{ FSP } & \multicolumn{3}{|c|}{$\begin{array}{c}\text { PANES } \\
\text { HS attendance (FSP) }\end{array}$} & \multicolumn{3}{|c|}{ FSP and SER } \\
\hline & Obs. & Mean & S.D & Obs. & Mean & S.D & Obs. & Mean & S.D \\
\hline \multicolumn{10}{|l|}{ Age 12-18 } \\
\hline Attendance & 3090 & 0.746 & 0.435 & & & & & & \\
\hline Age & 3093 & 14.83 & 2.014 & 1330 & 14.60 & 1.769 & 707 & 14.11 & 1.566 \\
\hline Treatment & 3093 & 0.701 & 0.458 & 1330 & 0.689 & 0.463 & 707 & 0.680 & 0.466 \\
\hline \multicolumn{10}{|c|}{ Home Production } \\
\hline 0 & 3079 & 0.333 & 0.471 & 1322 & 0.332 & 0.471 & 703 & 0.354 & 0.478 \\
\hline $0-10$ & 3079 & 0.315 & 0.464 & 1322 & 0.378 & 0.485 & 703 & 0.404 & 0.491 \\
\hline$>10$ & 3079 & 0.351 & 0.477 & 1322 & 0.290 & 0.453 & 703 & 0.242 & 0.428 \\
\hline \multicolumn{10}{|l|}{ GPA } \\
\hline $\mathrm{F}$ & & & & & & & 707 & 0.349 & 0.477 \\
\hline B & & & & & & & 707 & 0.444 & 0.497 \\
\hline $\mathrm{A}$ & & & & & & & 707 & 0.206 & 0.405 \\
\hline \multicolumn{10}{|l|}{ Grade } \\
\hline $1-2$ & & & & & & & 707 & 0.584 & 0.493 \\
\hline $3-4$ & & & & & & & 707 & 0.328 & 0.470 \\
\hline $5-6$ & & & & & & & 707 & 0.088 & 0.283 \\
\hline \multirow{2}{*}{\multicolumn{10}{|c|}{$\begin{array}{l}\text { Age 14-18 } \\
\text { Hours }\end{array}$}} \\
\hline \multicolumn{4}{|l|}{ Hours } & & & & & & \\
\hline 0 & 2093 & 0.823 & 0.381 & 903 & 0.905 & 0.294 & 423 & 0.941 & 0.236 \\
\hline $0-15$ & 2093 & 0.062 & 0.241 & 903 & 0.041 & 0.198 & 423 & 0.031 & 0.173 \\
\hline \multirow[t]{4}{*}{$>15$} & 2093 & 0.097 & 0.296 & 903 & 0.043 & 0.203 & 423 & 0.021 & 0.144 \\
\hline & \multirow{2}{*}{\multicolumn{3}{|c|}{ FSA }} & \multirow{2}{*}{\multicolumn{3}{|c|}{$\begin{array}{c}\text { AFAM } \\
\text { HS attendance (FSA) }\end{array}$}} & \multirow{2}{*}{\multicolumn{3}{|c|}{ FSA and SER }} \\
\hline & & & & & & & & & \\
\hline & Obs. & Mean & S.D & Obs. & Mean & S.D & Obs. & Mean & S.D \\
\hline \multicolumn{10}{|l|}{ Age 12-18 } \\
\hline Attendance & 2796 & 0.821 & 0.382 & & & & & & \\
\hline Age & 2936 & 14.93 & 1.0 & 1555 & 14.82 & 1.72 & 952 & 14.43 & 1.47 \\
\hline Treatment & 2936 & 0.731 & 0,443 & 1555 & 0.692 & 0.462 & 952 & 0.721 & 0.448 \\
\hline \multicolumn{10}{|c|}{ Home Production } \\
\hline 0 & 2641 & 0.141 & 0.348 & 1484 & 0.127 & 0.333 & 917 & 0.154 & 0.361 \\
\hline $0-10$ & 2641 & 0.541 & 0.498 & 1484 & 0.582 & 0.493 & 917 & 0.581 & 0.493 \\
\hline$>10$ & 2641 & 0.318 & 0.466 & 1484 & 0.291 & 0.454 & 917 & 0.265 & 0.441 \\
\hline \multicolumn{10}{|l|}{ Grade } \\
\hline $1-2$ & & & & & & & 952 & 0.574 & 0.494 \\
\hline $3-4$ & & & & & & & 952 & 0.425 & 0.494 \\
\hline \multirow{2}{*}{\multicolumn{10}{|c|}{$\begin{array}{l}\text { Age 14-18 } \\
\text { Hours }\end{array}$}} \\
\hline & & & & & & & & & \\
\hline 0 & 1901 & 0.868 & 0.338 & 1116 & 0.945 & 0.227 & 644 & 0.973 & 0.160 \\
\hline $0-15$ & 1901 & 0.03 & 0.180 & 1116 & 0.02 & 0.142 & 644 & 0.01 & 0.103 \\
\hline$>15$ & 1901 & 0.10 & 0.297 & 1116 & 0.04 & 0.181 & 644 & 0.016 & 0.123 \\
\hline
\end{tabular}


Table 3: Decisions by Age Group

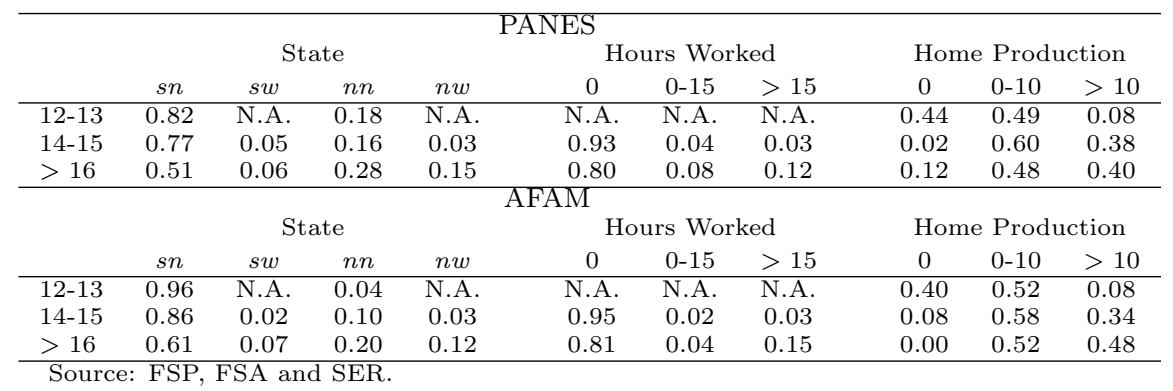

Table 4: The Grades Distribution by Age Group

\begin{tabular}{lcccccc}
\hline GPA & \multicolumn{3}{c}{ Age } & & & Grade \\
& $12-13$ & $14-15$ & $>16$ & $1-2$ & $3-4$ & $5-6$ \\
\hline $\mathrm{F}$ & 0.22 & 0.40 & 0.64 & 0.34 & 0.33 & 0.72 \\
$\mathrm{~B}$ & 0.50 & 0.43 & 0.26 & 0.44 & 0.46 & 0.18 \\
$\mathrm{~A}$ & 0.28 & 0.17 & 0.10 & 0.22 & 0.21 & 0.10 \\
Total & 100.0 & 100.0 & 100.0 & 100.0 & 100.0 & 100.0 \\
\hline \multicolumn{2}{l}{ Source: } & FSP and SER. & & & &
\end{tabular}

Table 5: Transitions of States

\begin{tabular}{|c|c|c|c|c|c|}
\hline & $s n_{t-1}$ & $s w_{t-1}$ & $n n_{t-1}$ & $n w_{t-1}$ & Tota \\
\hline$s n_{t}$ & 54.6 & 3.1 & 2.3 & 5.0 & 65.0 \\
\hline$s w_{t}$ & 4.4 & 0.6 & 0.4 & 0.6 & 5.9 \\
\hline$n n_{t}$ & 10.7 & 0.9 & 4.2 & 3.2 & 19.1 \\
\hline$n w_{t}$ & 4.9 & 0.7 & 1.5 & 2.8 & 10.0 \\
\hline Total & 74.6 & 5.2 & 8.5 & 11.7 & 100.0 \\
\hline \multicolumn{6}{|c|}{ State Distribution of $t$ on $t-1$} \\
\hline & $s n_{t-1}$ & $s w_{t-1}$ & $n n_{t-1}$ & $n w_{t-1}$ & \\
\hline$s n_{t}$ & 73.2 & 58.4 & 27.8 & 42.9 & \\
\hline$s w_{t}$ & 5.9 & 10.9 & 4.3 & 5.4 & \\
\hline$n n_{t}$ & 14.3 & 16.8 & 50.0 & 27.7 & \\
\hline$n w_{t}$ & 6.6 & 13.9 & 17.9 & 24.1 & \\
\hline Total & 100.0 & 100.0 & 100.0 & 100.0 & \\
\hline
\end{tabular}

Table 6: Age and Treatment Distribution at the Entrance Moment

\begin{tabular}{|c|c|c|c|c|c|c|}
\hline \multirow[b]{2}{*}{ Age } & \multicolumn{3}{|c|}{ PANES } & \multicolumn{3}{|c|}{$\overline{\text { AFAM }}$} \\
\hline & Total & Treated & Control & Total & Treated & Control \\
\hline 12 & 17.4 & 11.9 & 5.5 & 17.0 & 12.9 & 4.1 \\
\hline 13 & 16.6 & 12.6 & 4.1 & 15.2 & 11.9 & 3.3 \\
\hline 14 & 17.1 & 11.2 & 5.9 & 18.3 & 13.4 & 4.9 \\
\hline 15 & 16.1 & 11.2 & 4.9 & 16.6 & 11.7 & 4.9 \\
\hline 16 & 17.6 & 13.6 & 3.9 & 16.6 & 12.3 & 4.3 \\
\hline 17 & 15.2 & 11.1 & 4.2 & 16.3 & 12.0 & 4.3 \\
\hline
\end{tabular}

Table 7: Education Background at the Moment of Entering in PANES

\begin{tabular}{|c|c|c|c|c|c|c|c|c|}
\hline \multirow[t]{2}{*}{ Age } & \multicolumn{2}{|c|}{ Primary } & \multicolumn{6}{|c|}{ Middle and High school } \\
\hline & Not Completed & Completed & 1 & 2 & 3 & 4 & 5 & 6 \\
\hline \multicolumn{9}{|c|}{ Total } \\
\hline 12 & 76.6 & 23.4 & & & & & & \\
\hline 13 & 49.8 & 28.1 & 22.1 & & & & & \\
\hline 14 & 34.5 & 20.9 & 26.3 & 18.3 & & & & \\
\hline 15 & 31.7 & 14.5 & 21.0 & 19.9 & 12.9 & & & \\
\hline 16 & 31.1 & 9.7 & 18.3 & 16.6 & 16.0 & 8.3 & & \\
\hline 17 & 33.6 & 6.7 & 15.7 & 15.3 & 14.3 & 9.4 & 5.0 & \\
\hline \multicolumn{9}{|c|}{ Treated } \\
\hline 12 & 79.4 & 20.6 & & & & & & \\
\hline 13 & 54.3 & 26.3 & 19.4 & & & & & \\
\hline 14 & 39.0 & 20.9 & 24.3 & 15.8 & & & & \\
\hline 15 & 36.8 & 14.8 & 20.5 & 17.5 & 10.4 & & & \\
\hline 16 & 35.8 & 10.0 & 18.5 & 15.7 & 13.6 & 6.4 & & \\
\hline 17 & 38.2 & 6.6 & 16.0 & 14.5 & 12.9 & 8.0 & 3.8 & \\
\hline \multicolumn{9}{|c|}{ Control } \\
\hline 12 & 69.0 & 31.0 & & & & & & \\
\hline 13 & 38.1 & 32.8 & 29.1 & & & & & \\
\hline 14 & 23.9 & 20.8 & 30.8 & 24.5 & & & & \\
\hline 15 & 19.7 & 13.9 & 22.2 & 25.4 & 18.8 & & & \\
\hline 16 & 20.4 & 9.0 & 17.8 & 18.5 & 21.4 & 12.9 & & \\
\hline 17 & 23.8 & 6.9 & 15.2 & 16.8 & 17.2 & 12.5 & 7.6 & \\
\hline
\end{tabular}


Table 8: Education Background at the Time of Entering in AFAM

\begin{tabular}{|c|c|c|c|c|c|c|c|c|}
\hline \multirow[t]{2}{*}{ Age } & \multicolumn{2}{|c|}{ Primary } & \multicolumn{6}{|c|}{ Middle and High school } \\
\hline & Not Completed & Completed & 1 & 2 & 3 & 4 & 5 & 6 \\
\hline \multicolumn{9}{|c|}{ Total } \\
\hline 12 & 67.3 & 32.7 & & & & & & \\
\hline 13 & 34.2 & 21.4 & 44.4 & & & & & \\
\hline 14 & 24.8 & 9.5 & 30.1 & 35.6 & & & & \\
\hline 15 & 18.9 & 10.5 & 27.4 & 22.1 & 21.1 & & & \\
\hline 16 & 18.0 & 9.5 & 33.3 & 23.5 & 13.9 & 1.8 & & \\
\hline 17 & 19.7 & 4.0 & 24.0 & 32.1 & 17.2 & 1.8 & 1.2 & \\
\hline \multicolumn{9}{|c|}{ Treated } \\
\hline 12 & 69.8 & 30.2 & & & & & & \\
\hline 13 & 37.1 & 18.8 & 44.1 & & & & & \\
\hline 14 & 28.0 & 10.6 & 29.6 & 31.8 & & & & \\
\hline 15 & 19.6 & 9.6 & 28.8 & 19.9 & 22.1 & & & \\
\hline 16 & 20.1 & 9.8 & 31.7 & 23.6 & 13.0 & 1.8 & & \\
\hline 17 & 23.4 & 4.7 & 23.4 & 30.4 & 16.4 & 1.3 & 0.4 & \\
\hline \multicolumn{9}{|c|}{ Control } \\
\hline 12 & 59.4 & 40.6 & & & & & & \\
\hline 13 & 24.2 & 30.3 & 45.5 & & & & & \\
\hline 14 & 15.8 & 6.3 & 31.6 & 46.3 & & & & \\
\hline 15 & 17.3 & 12.6 & 24.4 & 26.8 & 18.9 & & & \\
\hline 16 & 12.5 & 8.6 & 37.5 & 23.1 & 16.4 & 1.9 & & \\
\hline 17 & 8.2 & 2.1 & 25.8 & 37.1 & 19.6 & 3.1 & 4.1 & \\
\hline
\end{tabular}

Table 9: Wage Equation

\begin{tabular}{|c|c|c|c|}
\hline Dependent variable: wage ( $15-18$ years) & $\begin{array}{l}\text { OLS } \\
(1)\end{array}$ & $\begin{array}{l}\text { Heckman } \\
(2)\end{array}$ & $\begin{array}{c}\text { Selection eq. } \operatorname{Pr}(\text { work }=1) \\
(3)\end{array}$ \\
\hline \multirow[t]{2}{*}{ Age } & 0.063 & 0.155 & $0.224 * * *$ \\
\hline & {$[0.105]$} & {$[0.195]$} & {$[0.038]$} \\
\hline \multirow{2}{*}{ Attendance $(1=$ Yes $)$} & -0.030 & -0.339 & $-0.719 * * *$ \\
\hline & {$[0.262]$} & [0.612] & {$[0.092]$} \\
\hline \multicolumn{4}{|l|}{ Education (Ref: Primary) } \\
\hline Middle School & $\begin{array}{c}-0.460^{*} \\
{[0.245]}\end{array}$ & $\begin{array}{c}-0.448^{*} \\
{[0.245]}\end{array}$ & $\begin{array}{c}0.022 \\
{[0.099]}\end{array}$ \\
\hline High School & $\begin{array}{c}-0.856^{* *} \\
{[0.378]}\end{array}$ & $\begin{array}{c}-0.918^{* *} \\
{[0.392]}\end{array}$ & $\begin{array}{l}-0.153 \\
{[0.136]}\end{array}$ \\
\hline \multicolumn{4}{|l|}{ Home Production (Ref: $\mathrm{HP}=0$ ) } \\
\hline $0-10$ & $\begin{array}{c}0.742^{* *} \\
{[0.379]}\end{array}$ & $\begin{array}{l}0.719^{*} \\
{[0.379]}\end{array}$ & $\begin{array}{l}-0.062 \\
{[0.133]}\end{array}$ \\
\hline$>10$ & $\begin{array}{l}0.813^{* *} \\
{[0.336]}\end{array}$ & $\begin{array}{l}0.740 * * \\
{[0.358]}\end{array}$ & $\begin{array}{l}-0.122 \\
{[0.120]}\end{array}$ \\
\hline Treated $(1=$ Yes $)$ & $\begin{array}{c}0.272 \\
{[0.220]}\end{array}$ & $\begin{array}{c}0.271 \\
{[0.219]}\end{array}$ & $\begin{array}{c}0.013 \\
{[0.082]}\end{array}$ \\
\hline 2nd Wave $(1=$ Yes $)$ & $\begin{array}{c}0.337 \\
{[0.207]}\end{array}$ & $\begin{array}{c}0.336 \\
{[0.206]}\end{array}$ & $\begin{array}{l}-0.012 \\
{[0.077]}\end{array}$ \\
\hline Offspring ( $1=$ Yes) & & & $\begin{array}{c}-0.713^{* * * *} \\
{[0.181]}\end{array}$ \\
\hline Constant & $\begin{array}{c}1.465 \\
{[1.720]}\end{array}$ & $\begin{array}{l}-0.640 \\
{[4.149]}\end{array}$ & $\begin{array}{c}-4.094^{* * * *} \\
{[0.636]}\end{array}$ \\
\hline Mills & & & $\begin{array}{c}0.553 \\
{[0.992]}\end{array}$ \\
\hline $\begin{array}{l}\mathrm{N} \\
\mathrm{R} \text {-sq }\end{array}$ & $\begin{array}{c}302 \\
0.064\end{array}$ & & 1568 \\
\hline
\end{tabular}


Table 10: Home Production: OLS

\begin{tabular}{|c|c|c|c|}
\hline & All & Under-19 & Under-19 $(\mathrm{CCT})^{*}$ \\
\hline \multicolumn{4}{|l|}{ Age (reference: 12-13) } \\
\hline $14-15$ & $\begin{array}{c}10.308^{* * *} \\
{[1.690]}\end{array}$ & $\begin{array}{l}9.148^{* * *} \\
{[0.900]}\end{array}$ & $\begin{array}{c}6.814^{* * *} \\
{[2.445]}\end{array}$ \\
\hline $16-17$ & $\begin{array}{c}10.032 * * * \\
{[1.716]}\end{array}$ & $\begin{array}{c}9.013^{* * *} \\
{[0.938]}\end{array}$ & $\begin{array}{c}9.584^{* * *} * \\
{[2.533]}\end{array}$ \\
\hline $18-19$ & $\begin{array}{c}15.080^{* * *} \\
{[1.828]}\end{array}$ & $\begin{array}{c}10.804 * * * \\
{[1.081]}\end{array}$ & $\begin{array}{c}14.615^{* * *} \\
{[3.290]}\end{array}$ \\
\hline 20 or more & $\begin{array}{c}19.031 * * * \\
{[1.531]}\end{array}$ & & \\
\hline Sex $(1=$ Male $)$ & $\begin{array}{l}-21.199^{* * *} \\
{[0.503]}\end{array}$ & $\begin{array}{c}-5.332 * * * \\
{[0.637]}\end{array}$ & $\begin{array}{c}-6.896 * * * \\
{[1.817]}\end{array}$ \\
\hline Region ( $1=$ Capital City) & $\begin{array}{c}-1.300^{* *} \\
{[0.525]}\end{array}$ & $\begin{array}{l}1.399^{*} \\
{[0.781]}\end{array}$ & $\begin{array}{c}3952 \\
{[2.696]}\end{array}$ \\
\hline Employee $(1=$ Yes $)$ & $\begin{array}{l}-5.613^{* * * *} \\
{[0.540]}\end{array}$ & $\begin{array}{c}-2.572^{* *} \\
{[1.066]}\end{array}$ & $\begin{array}{l}-6.432^{*} \\
{[3.560]}\end{array}$ \\
\hline Attendance $(1=$ Yes. $0=$ No $)$ & $\begin{array}{l}-5.550 * * * \\
{[0.962]}\end{array}$ & $\begin{array}{c}-3.634 * * * \\
{[0.876]}\end{array}$ & $\begin{array}{c}-5.395 * * \\
{[2.708]}\end{array}$ \\
\hline Offspring ( $1=$ Yes) & $\begin{array}{c}12.995 * * * \\
{[0.634]}\end{array}$ & $\begin{array}{c}45.903^{* * *} \\
{[1.910]}\end{array}$ & $\begin{array}{c}36.838 * * * \\
{[5.805]}\end{array}$ \\
\hline Household Income/100 & $\begin{array}{l}-0.001 \\
{[0.002]}\end{array}$ & $\begin{array}{l}-0.001 \\
{[0.003]}\end{array}$ & $\begin{array}{c}0.007 \\
{[0.043]}\end{array}$ \\
\hline Constant & $\begin{array}{c}16.145^{* * *} \\
{[1.521]}\end{array}$ & $\begin{array}{l}6.276^{* * *} \\
{[1.136]}\end{array}$ & $\begin{array}{l}8.971 * * \\
{[3.691]}\end{array}$ \\
\hline $\mathrm{N}$ & 9387 & 1481 & 196 \\
\hline $\mathrm{R}$-square & 0.3061 & 0.4541 & 0.4465 \\
\hline
\end{tabular}

Table 11: GPA: Ordered Probit

\begin{tabular}{|c|c|c|c|c|c|c|}
\hline \multirow{3}{*}{ Dependent variable: GPA } & \multirow{2}{*}{\multicolumn{4}{|c|}{ Age }} & \multirow{2}{*}{\multicolumn{2}{|c|}{$15-18$}} \\
\hline & & & & & & \\
\hline & (1) & $(2)$ & (3) & (4) & (5) & (6) \\
\hline \multicolumn{7}{|l|}{ GPA t-1 (ref: F) } \\
\hline $\mathrm{B}$ & $0.645^{* * *}$ & $0.631 * * *$ & $0.883^{* * *}$ & $0.866^{* * *}$ & 0.069 & 0.058 \\
\hline $\mathrm{A}$ & $\begin{array}{c}1.720^{* * *} \\
{[0.183]}\end{array}$ & $\begin{array}{c}1.685^{* * *} \\
{[0.184]}\end{array}$ & $\begin{array}{c}1.892^{* * *} \\
{[0.209]}\end{array}$ & $\begin{array}{c}{\left[.863^{* * *}\right.} \\
{[0.209]}\end{array}$ & $\begin{array}{c}{\left[.784^{* * *}\right.} \\
{[0.497]}\end{array}$ & $\begin{array}{c}{\left[.738^{* * *}\right.} \\
{[0.497]}\end{array}$ \\
\hline \multicolumn{7}{|l|}{ Grade (ref:1-2) } \\
\hline $3-4$ & $\begin{array}{c}0.192 \\
{[0.138]}\end{array}$ & $\begin{array}{c}0.212 \\
{[0.139]}\end{array}$ & $\begin{array}{c}0.362^{* *} \\
{[0.184]}\end{array}$ & $\begin{array}{c}0.385^{* *} \\
{[0.185]}\end{array}$ & $\begin{array}{c}0.018 \\
{[0.222]}\end{array}$ & $\begin{array}{c}0.019 \\
{[0.225]}\end{array}$ \\
\hline $5-6$ & $\begin{array}{c}-0.384 \\
{[0.3220]}\end{array}$ & $\begin{array}{l}-0.373 \\
{[0.321]}\end{array}$ & & & $\begin{array}{c}-1.063 * * * \\
{[0.357]}\end{array}$ & $\begin{array}{c}-1.045^{* * *} \\
{[0.359]}\end{array}$ \\
\hline Sex $(1=$ Male $)$ & & $\begin{array}{l}-0.219 \\
{[0.134]}\end{array}$ & & $\begin{array}{l}-0.192 \\
{[0.186]}\end{array}$ & & $\begin{array}{l}-0.140 \\
{[0.206]}\end{array}$ \\
\hline Age & $\begin{array}{c}-0.127 * * \\
{[0.056]}\end{array}$ & $\begin{array}{c}-0.128^{* *} \\
{[0.057]}\end{array}$ & $\begin{array}{c}-0.257^{* * *} \\
{[0.091]}\end{array}$ & $\begin{array}{c}-0.259^{* * * *} \\
{[0.094]}\end{array}$ & $\begin{array}{c}0.169 \\
{[0.114]}\end{array}$ & $\begin{array}{c}0.149 \\
{[0.114]}\end{array}$ \\
\hline \multicolumn{7}{|l|}{ Home Production (Ref: $\mathrm{HP}=0$ ) } \\
\hline $0-10$ & $\begin{array}{c}0.097 \\
{[0.102]}\end{array}$ & $\begin{array}{l}-0.047 \\
{[0.143]}\end{array}$ & $\begin{array}{c}0.121 \\
{[0.114]}\end{array}$ & $\begin{array}{l}-0.008 \\
{[0.187]}\end{array}$ & $\begin{array}{c}0.032 \\
{[0.313]}\end{array}$ & $\begin{array}{l}-0.029 \\
{[0.321]}\end{array}$ \\
\hline$>10$ & $\begin{array}{c}0.077 \\
{[0.162]}\end{array}$ & $\begin{array}{l}-0.009 \\
{[0.185]}\end{array}$ & $\begin{array}{c}0.084 \\
{[0.328]}\end{array}$ & $\begin{array}{l}-0.119 \\
{[0.386]}\end{array}$ & $\begin{array}{c}0.166 \\
0.276]\end{array}$ & $\begin{array}{c}0.104 \\
{[0.286]}\end{array}$ \\
\hline Region ( $1=$ Capital City) & & $\begin{array}{l}-0.197 \\
{[0.149]}\end{array}$ & & $\begin{array}{l}-0.296 \\
{[0.207]}\end{array}$ & & $\begin{array}{l}-0.013 \\
{[0.201]}\end{array}$ \\
\hline Treated $(1=$ Yes $)$ & $\begin{array}{c}0.119 \\
{[0.107]}\end{array}$ & $\begin{array}{c}0.130 \\
{[0.107]}\end{array}$ & $\begin{array}{c}0.194 \\
{[0.127]}\end{array}$ & $\begin{array}{c}0.206 \\
{[0.128]}\end{array}$ & $\begin{array}{c}0.046 \\
{[0.199]}\end{array}$ & $\begin{array}{c}0.051 \\
{[0.204]}\end{array}$ \\
\hline 2nd Wave $(1=$ Yes $)$ & & $\begin{array}{c}-0.156^{*} \\
{[0.095]}\end{array}$ & & $\begin{array}{c}-0.187^{*} \\
{[0.128]}\end{array}$ & & $\begin{array}{l}-0.114 \\
{[0.184]}\end{array}$ \\
\hline \multicolumn{7}{|l|}{ Hours Worked (Ref: HW=0) } \\
\hline $0-15$ & & & & & $\begin{array}{c}0.464 \\
{[0.673]}\end{array}$ & $\begin{array}{c}0.527 \\
{[0.684]}\end{array}$ \\
\hline$>15$ & & & & & $\begin{array}{l}-0.208 \\
{[0.347]}\end{array}$ & $\begin{array}{l}-0.133 \\
{[0.384]}\end{array}$ \\
\hline$\nu_{1}$ & $\begin{array}{l}-1.827 \\
{[0.736]}\end{array}$ & $\begin{array}{l}-2.117 \\
{[0.744]}\end{array}$ & $\begin{array}{l}-4.015 \\
{[1.273]}\end{array}$ & $\begin{array}{l}-3.682 \\
{[1.208]}\end{array}$ & $\begin{array}{l}2.508 \\
{[1.866]}\end{array}$ & $\begin{array}{c}2.021 \\
{[1.870]}\end{array}$ \\
\hline$\nu_{2}$ & $\begin{array}{l}-0.203 \\
{[0.732]}\end{array}$ & $\begin{array}{l}-0.479 \\
{[0.741]}\end{array}$ & $\begin{array}{c}-2.21 \\
{[1.266]}\end{array}$ & $\begin{array}{l}-1.868 \\
{[1.204]}\end{array}$ & $\begin{array}{c}3.866 \\
{[1.873]}\end{array}$ & $\begin{array}{c}3.384 \\
{[1.878]}\end{array}$ \\
\hline $\mathrm{N}$ & 623 & 623 & 454 & 454 & 169 & 169 \\
\hline Pseudo R-sq & 0.147 & 0.153 & 0.166 & 0.174 & 0.091 & 0.094 \\
\hline
\end{tabular}


Table 12: Transitions: Multinomial Logit 15-18 Years old

\begin{tabular}{|c|c|c|c|c|c|c|c|c|c|}
\hline & \multicolumn{9}{|c|}{ sn base outcome } \\
\hline & (1a) & $(1 \mathrm{~b})$ & (1c) & (2a) & $\begin{array}{c}\mathrm{nn} \\
(2 \mathrm{~b})\end{array}$ & $(2 \mathrm{c})$ & (3a) & $\begin{array}{l}\mathrm{nw} \\
(3 \mathrm{~b})\end{array}$ & (3c) \\
\hline State & & & & & & & & & \\
\hline sw & $\begin{array}{l}0.190 * * \\
{[0.561]}\end{array}$ & $\begin{array}{l}1.217^{* *} \\
{[0.556]}\end{array}$ & $\begin{array}{l}1.116^{* *} \\
{[0.564]}\end{array}$ & $\begin{array}{l}-0.552 \\
{[0.767]}\end{array}$ & $\begin{array}{l}-0.405 \\
{[0.721]}\end{array}$ & $\begin{array}{l}-0.488 \\
{[0.718]}\end{array}$ & $\begin{array}{l}1.016 \\
{[0.683]}\end{array}$ & $\begin{array}{l}1.166 \\
{[0.786]}\end{array}$ & $\begin{array}{c}0.870 \\
{[0.851]}\end{array}$ \\
\hline $\mathrm{nn}$ & $\begin{array}{c}0.482 \\
{[0.584]}\end{array}$ & $\begin{array}{c}0.593 \\
{[0.593]}\end{array}$ & $\begin{array}{c}0.624 \\
{[0.595]}\end{array}$ & $\begin{array}{c}2.160^{* * *} \\
{[0.290]}\end{array}$ & $\begin{array}{c}2.341^{* * *} \\
{[0.336]}\end{array}$ & $\begin{array}{c}2.385^{* * * *} \\
{[0.345]}\end{array}$ & $\begin{array}{c}2.567^{* * *} \\
{[0.391]}\end{array}$ & $\begin{array}{c}2.670^{* * * *} \\
{[0.439]}\end{array}$ & $\begin{array}{c}2.658^{* * *} \\
{[0.459]}\end{array}$ \\
\hline $\mathrm{nw}$ & $\begin{array}{c}0.350 \\
{[0.383]}\end{array}$ & $\begin{array}{l}0.438 \\
{[0.391]}\end{array}$ & $\begin{array}{l}0.456 \\
{[0.394]}\end{array}$ & $\begin{array}{c}1.243^{* * * *} \\
{[0.227]}\end{array}$ & $\begin{array}{c}1.202^{* * *} \\
{[0.242]}\end{array}$ & $\begin{array}{c}1.160^{* * * *} \\
{[0.245]}\end{array}$ & $\begin{array}{c}2.261^{* * *} \\
{[0.267]}\end{array}$ & $\begin{array}{c}2.176^{* * * *} \\
{[0.337]}\end{array}$ & $\begin{array}{c}1.930 * * * \\
{[0.348]}\end{array}$ \\
\hline Sex $(1=$ Male $)$ & & & $\begin{array}{c}0.321 \\
{[0.345]}\end{array}$ & & & $\begin{array}{c}0.670^{* * * *} \\
{[0.251]}\end{array}$ & & & $\begin{array}{c}2.251^{* * *} \\
{[0.366]}\end{array}$ \\
\hline Age & & $\begin{array}{c}0.153 \\
{[0.164]}\end{array}$ & $\begin{array}{c}0.137 \\
{[0.169]}\end{array}$ & & $\begin{array}{c}0.505^{* * *} \\
{[0.097]}\end{array}$ & $\begin{array}{c}0.551^{* * * *} \\
{[0.103]}\end{array}$ & & $\begin{array}{c}0.878^{* * *} \\
{[0.143]}\end{array}$ & $\begin{array}{c}1.010^{* * *} \\
{[0.153]}\end{array}$ \\
\hline Home Production $(\mathrm{HP}=0)$ & & & & & & & & & \\
\hline $0-10$ & & $\begin{array}{c}0.611 \\
{[0.510]}\end{array}$ & $\begin{array}{c}0.781 \\
{[0.561]}\end{array}$ & & $\begin{array}{l}-0.328 \\
{[0.426]}\end{array}$ & $\begin{array}{l}-0.216 \\
{[0.438]}\end{array}$ & & $\begin{array}{c}-1.444^{* *} \\
{[0.571]}\end{array}$ & $\begin{array}{c}-1.407^{* *} \\
{[0.653]}\end{array}$ \\
\hline$>10$ & & $\begin{array}{l}0.286 \\
{[0.506]}\end{array}$ & $\begin{array}{l}0.496 \\
{[0.548]}\end{array}$ & & $\begin{array}{c}1.326^{* * *} \\
{[0.340]}\end{array}$ & $\begin{array}{c}1.639^{* * *} \\
{[0.347]}\end{array}$ & & $\begin{array}{l}0.449 \\
{[0.408]}\end{array}$ & $\begin{array}{c}1.260^{* * *} \\
{[0.410]}\end{array}$ \\
\hline Region (1=Capital City) & & & $\begin{array}{l}-0.503 \\
{[0.524]}\end{array}$ & & & $\begin{array}{l}-0.117 \\
{[0.282]}\end{array}$ & & & $\begin{array}{c}-0.483^{* * *} \\
{[0.373]}\end{array}$ \\
\hline Treated $(1=$ Yes $)$ & & $\begin{array}{c}0.099 \\
{[0.370]}\end{array}$ & $\begin{array}{l}-0.043 \\
{[0.363]}\end{array}$ & & $\begin{array}{l}-0.038 \\
{[0.225]}\end{array}$ & $\begin{array}{l}-0.150 \\
{[0.231]}\end{array}$ & & $\begin{array}{l}-0.081 \\
{[0.276]}\end{array}$ & $\begin{array}{l}-0.214 \\
{[0.300]}\end{array}$ \\
\hline Constant & $\begin{array}{c}-2.353^{* * *} \\
{[0.228]}\end{array}$ & $\begin{array}{c}-5.337^{* *} \\
{[2.720]}\end{array}$ & $\begin{array}{c}-5.286^{*} \\
{[2.743]} \\
\end{array}$ & $\begin{array}{c}-1.526^{* * * *} \\
{[0.159]}\end{array}$ & $\begin{array}{c}-10.676^{* * * *} \\
{[1.588]}\end{array}$ & $\begin{array}{c}-11.875^{* * *} \\
{[1.732]}\end{array}$ & $\begin{array}{c}-2.690^{* * *} \\
{[0.267]}\end{array}$ & $\begin{array}{c}-17.300^{* * *} \\
{[2.329]}\end{array}$ & $\begin{array}{c}-21.192^{* * * *} \\
{[2.587]}\end{array}$ \\
\hline $\mathrm{N}$ & 659 & 653 & 653 & 659 & 653 & 653 & 659 & 653 & 653 \\
\hline Pseudo R-sq & 0.089 & 0.175 & 0.211 & 0.089 & 0.175 & 0.211 & 0.089 & 0.175 & 0.211 \\
\hline
\end{tabular}


Table 13: Estimation: Parameters Estimated by SMM

\begin{tabular}{cccc}
\hline & $12-13$ & $14-15$ & $16-17$ \\
\hline$\gamma_{t}$ & 0.3082 & 0.5808 & 0.7613 \\
& $(0.000344)$ & $(0.00235)$ & $(0.00255)$ \\
$b_{1 t}^{n}$ & 5.42 & 90.68 & 90.68 \\
& $(0.112)$ & $(31.76)$ & $(31.76)$ \\
$b_{2}^{n}$ & 8.99 & 8.99 & 8.99 \\
& $(0.343)$ & $(0.343)$ & $(0.343)$ \\
$b_{1 t}^{h p}$ & 262.95 & 121.69 & 198.03 \\
& $(37.15)$ & $(6.25)$ & $(10.34)$ \\
$b_{2}^{h p}$ & 6.89 & 6.89 & 6.89 \\
& $(0.228)$ & $(0.228)$ & $(0.228)$ \\
\hline
\end{tabular}

Table 14: Estimation: Parameters Estimated by SMM.

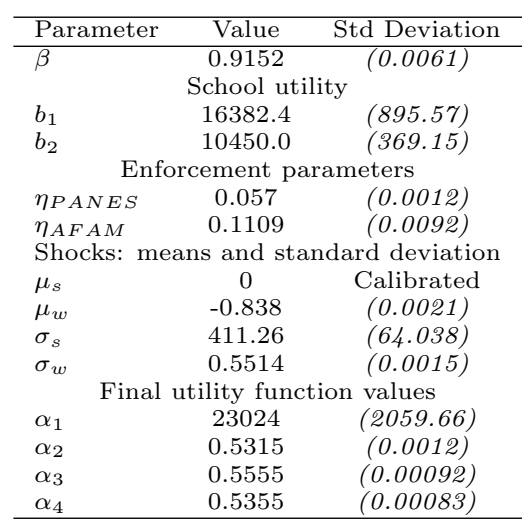




\section{Figures}

Figure 1: Model Fits: PANES Time Use Moments

\section{Model Matching (PANES)}
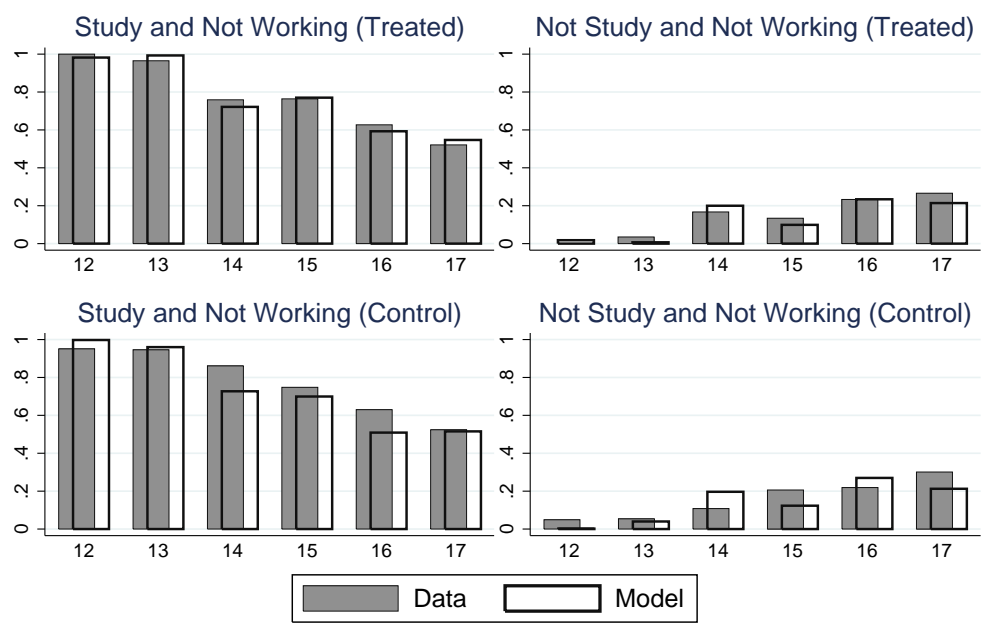

Figure 2: Model Fits: AFAM Time Use Moments

\section{Model Matching (AFAM)}
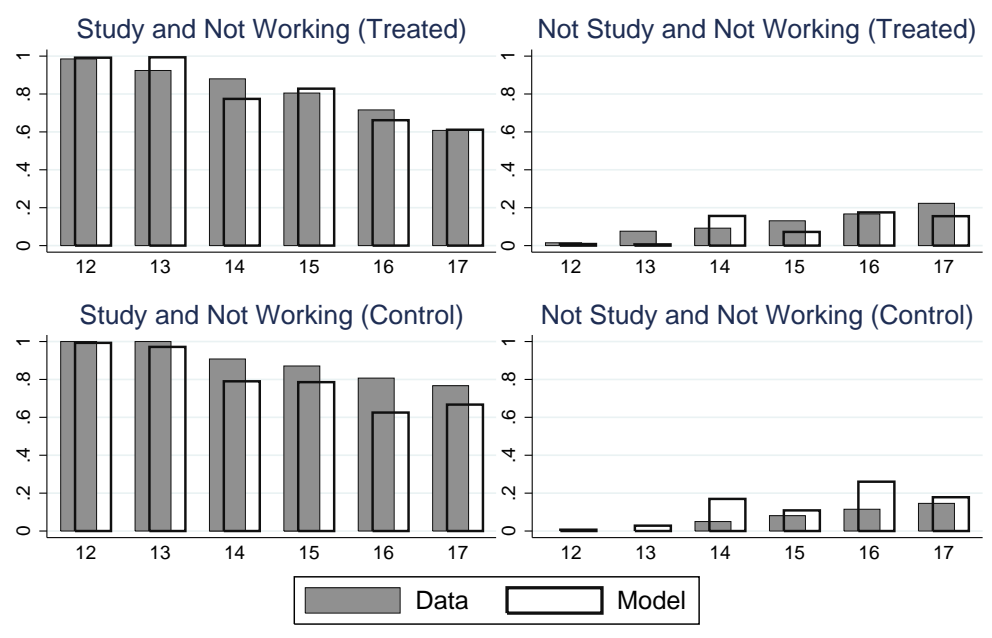
Figure 3: Model Fits: PANES Time Use Moments

Model Matching (PANES)
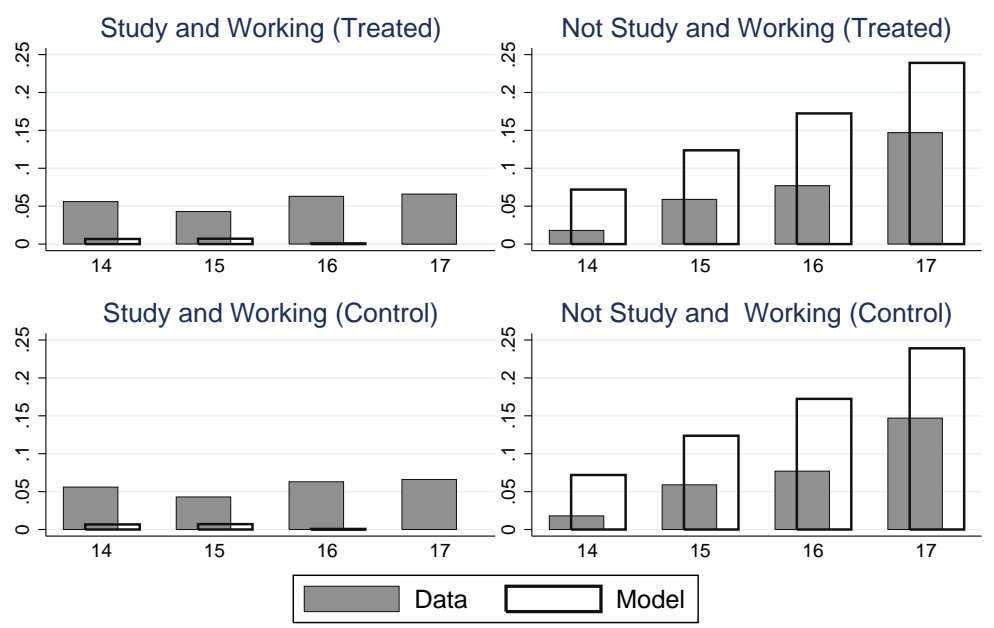

Figure 4: Model Fits: AFAM Time Use Moments

Model Matching (AFAM)

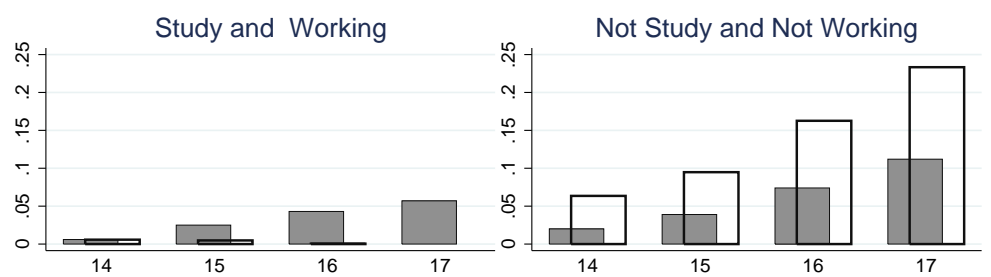

Study and Working

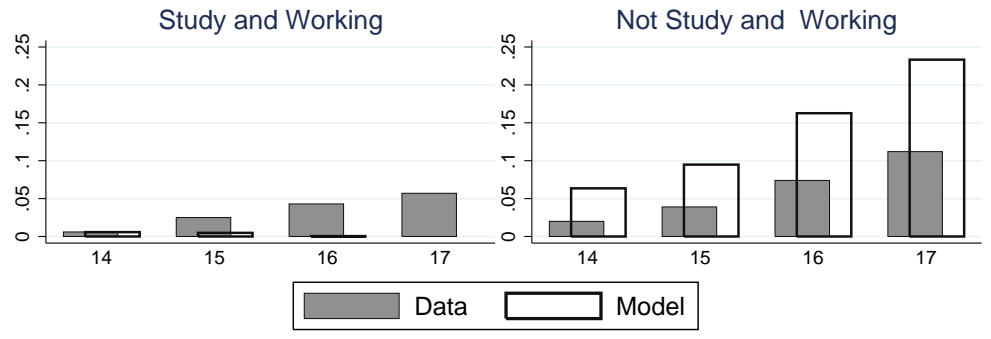


Figure 5: Model Fits: Home Production PANES

Model Matching - Home Production (PANES)

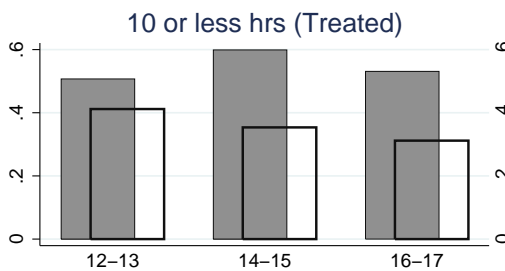

Greater than $10 \mathrm{hrs}$ (Treated)

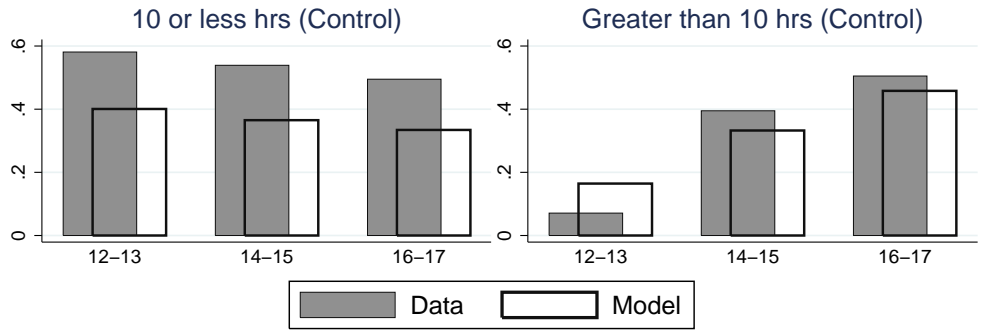

Figure 6: Model Fits: Home Production AFAM

Model Matching - Home Production (AFAM)

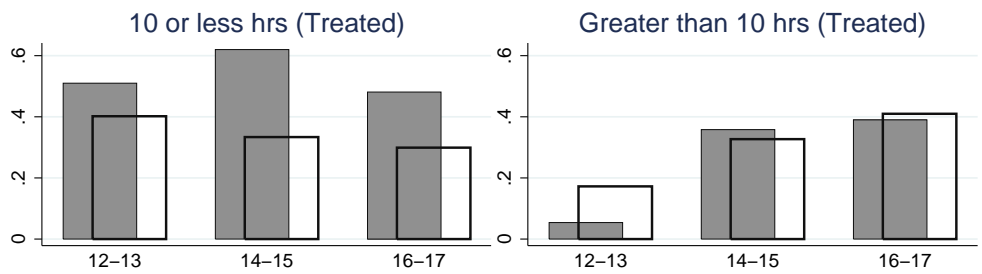

10 or less hrs (Control)

Greater 10 hrs (Control)

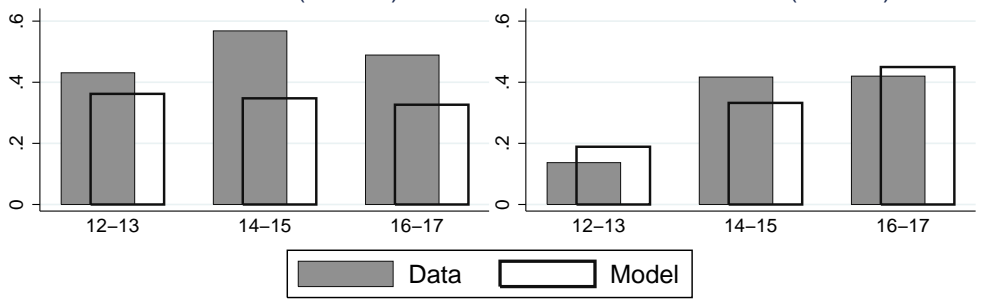


Figure 7: Model Fits: Working in the Market

\section{Model Matching - Working hrs (PANES \& AFAM)}
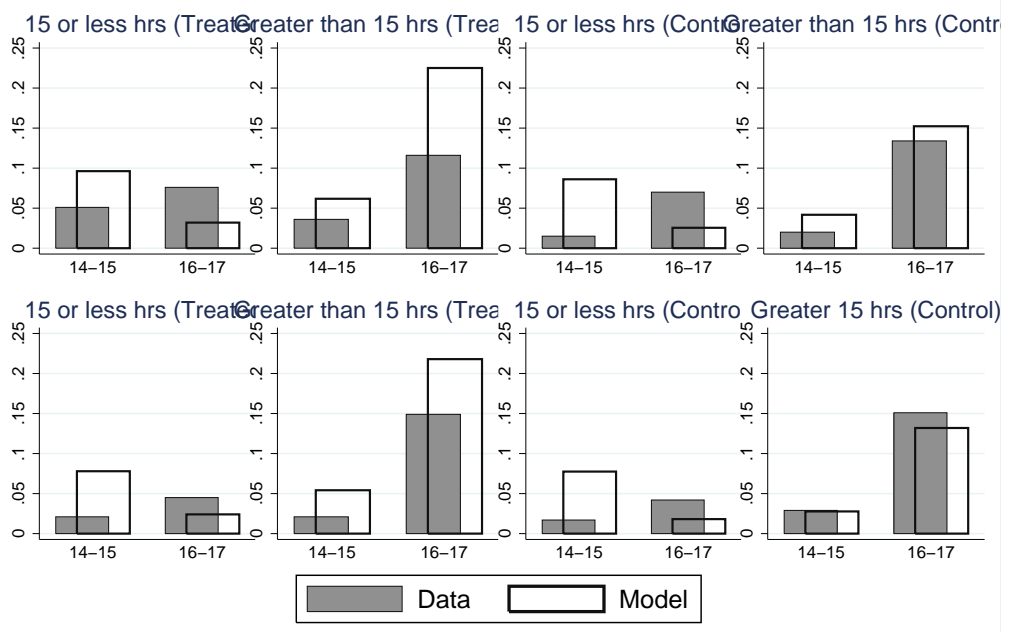

Figure 8: Model Fits: Grades Distribution

Model Fit: Grades by Age

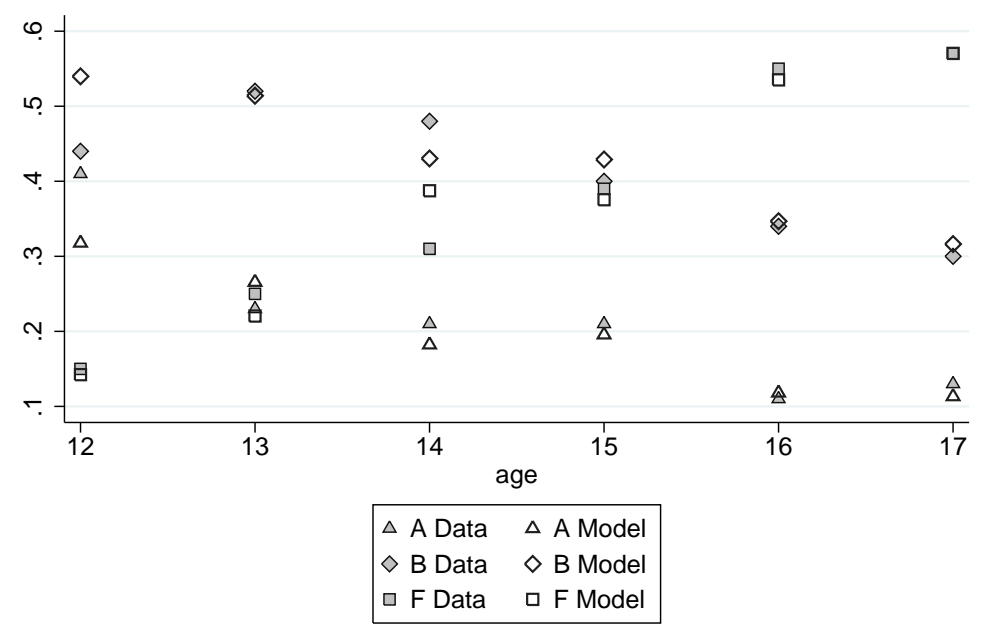


Figure 9: First Policy Experiment: Differences Between Treated and Control and Policy with a Small Increase of the Enforcement Parameter

\section{First Policy Experiment \\ Change in Time Use}

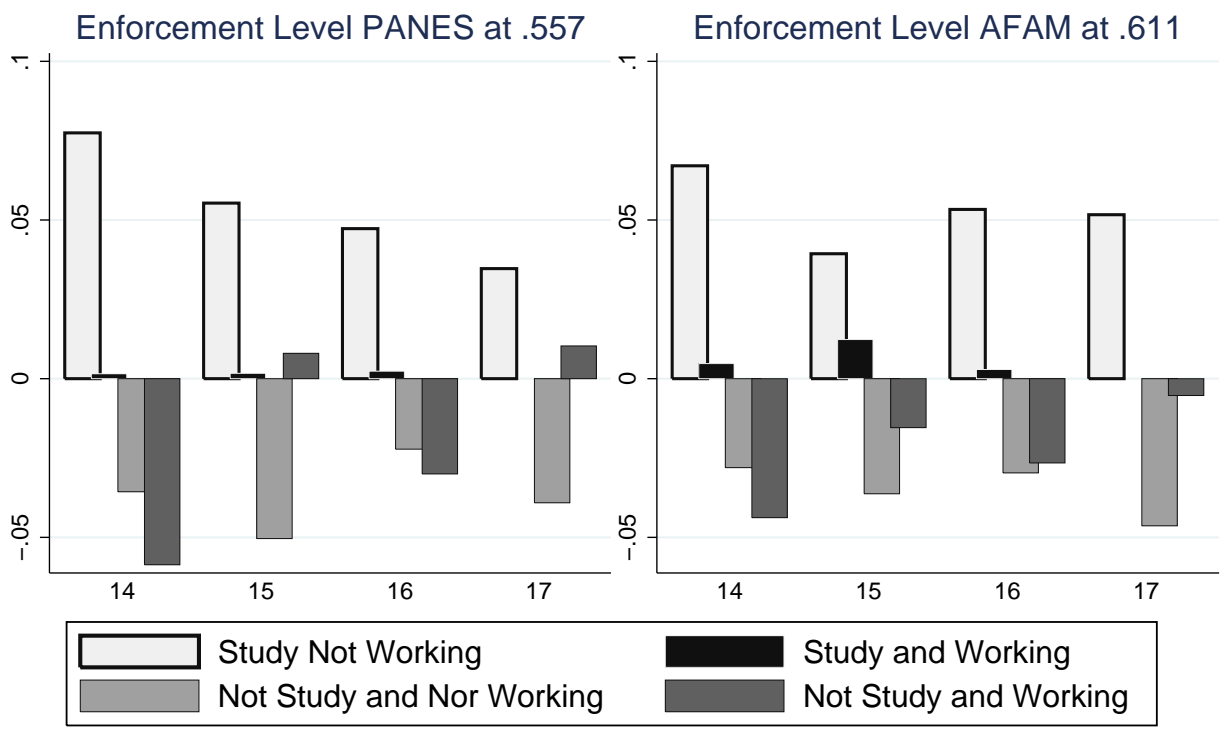

Figure 10: Second Policy Experiment: Differences Between Treated and Control and Policy with Maximum of the Enforcement Parameter

\section{Second Policy Experiment}

Change in Time Use

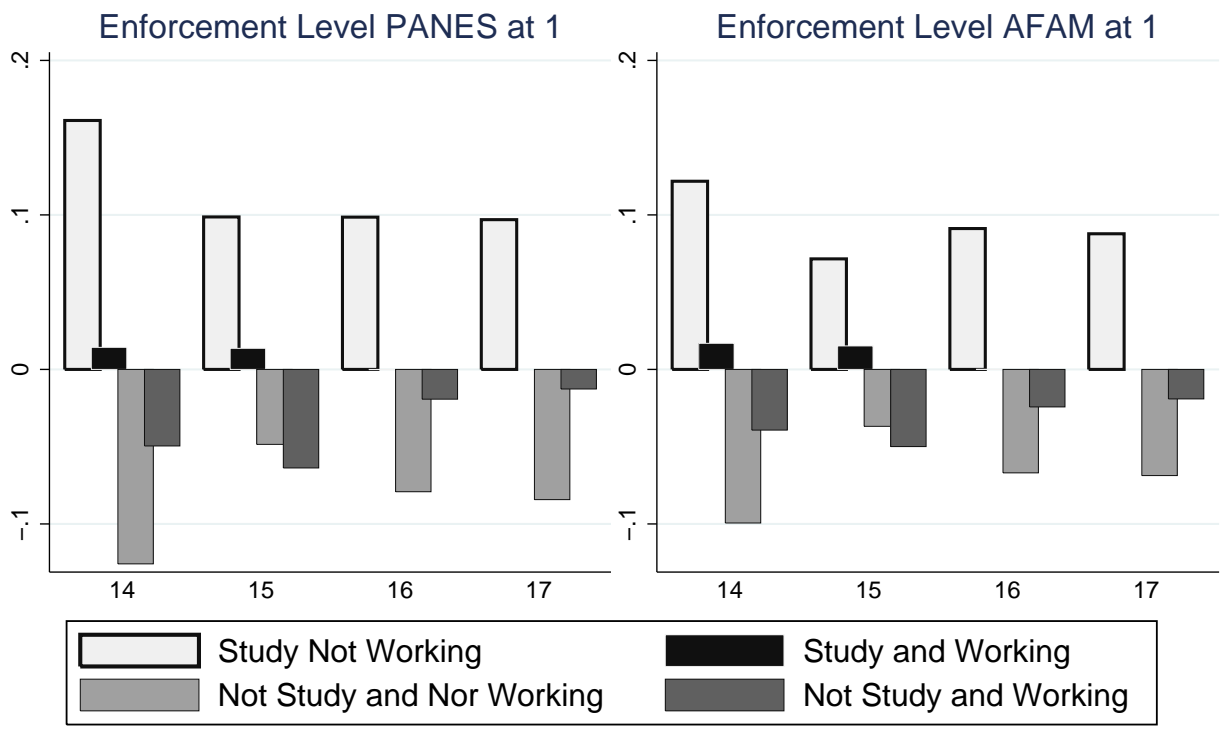


Figure 11: Third Policy Experiment: Differences Between Treated and Control and Policy of Change Who Receives the Transfer

\section{Third Policy Experiment \\ Change in Time Use}

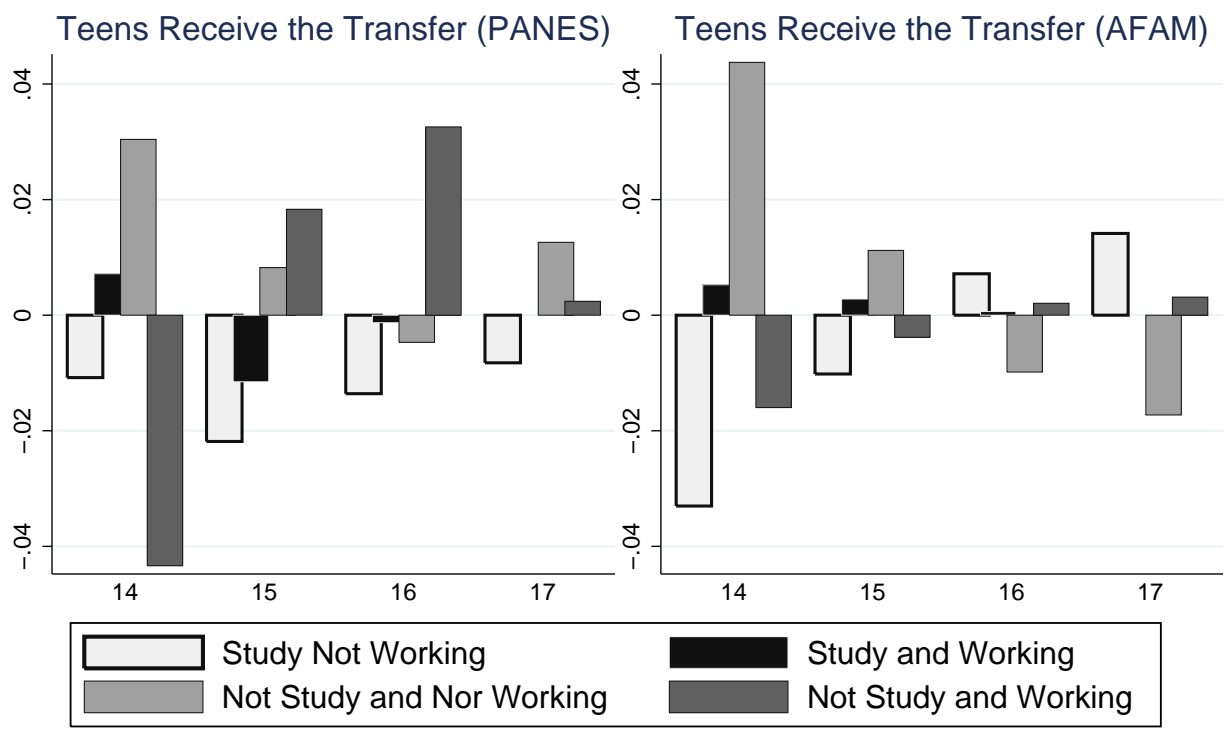

Figure 12: Fourth Policy Experiment: Differences Between Treated and Control and Policy of Change Who Receives the Transfer and Small Increase the Enforcement Parameter

\section{Fourth Policy Experiment \\ Change in Time Use}

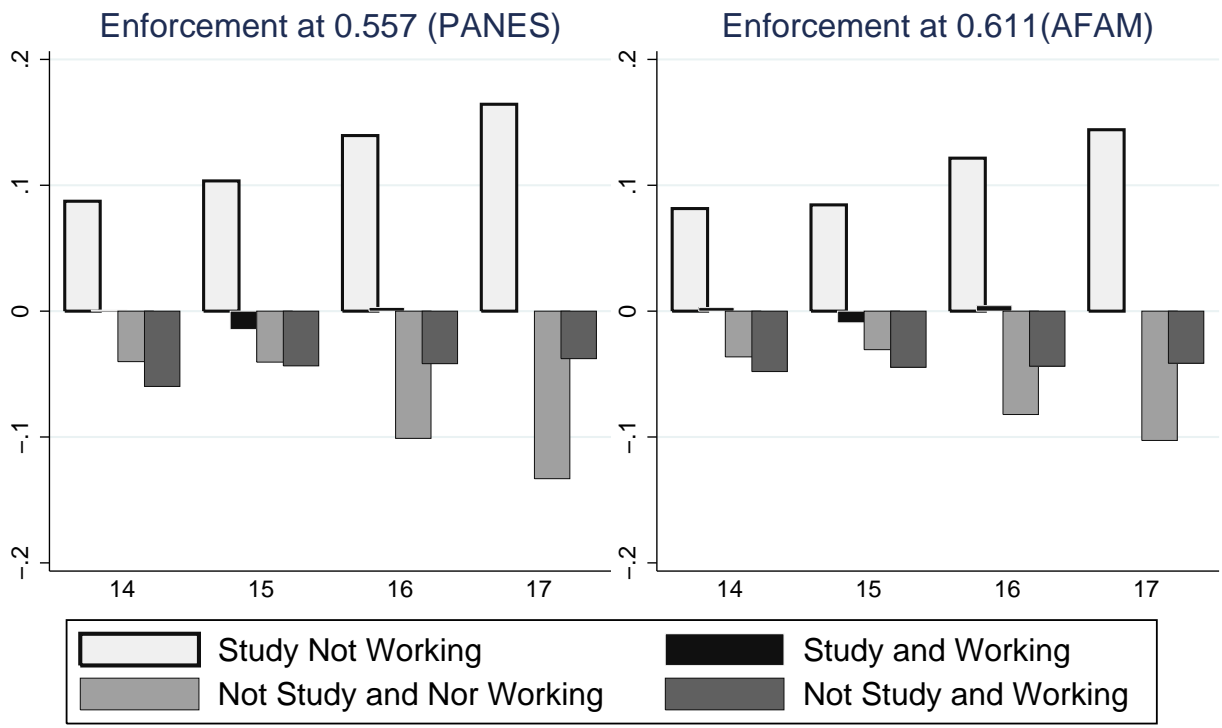


Figure 13: Fifth Policy Experiment: Differences Between Treated and Control and Policy of Change Who Receives the Transfer and Maximum Enforcement Parameter

\section{Fifth Policy Experiment}

Change in Time Use

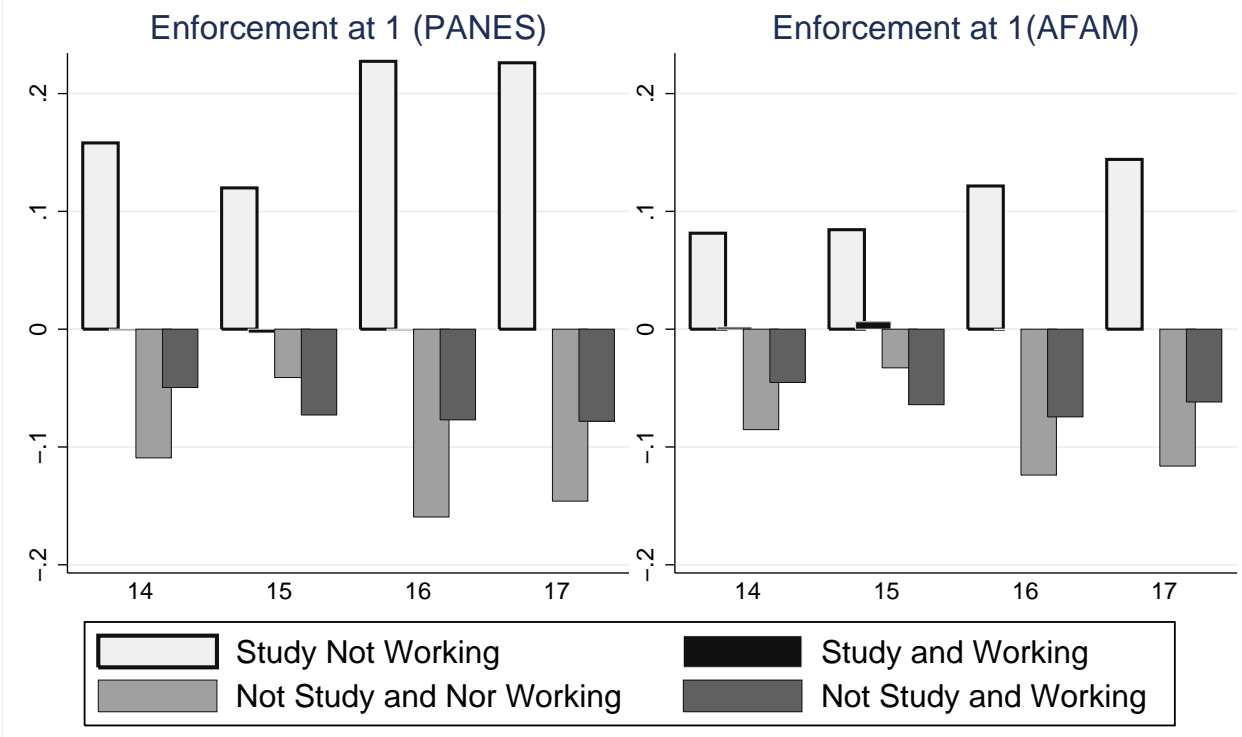




\section{Appendix}

Figure A.1: First Policy Experiment: Differences Between Treated and Control and Policy with a Small Increase of the Enforcement Parameter

\section{First Policy Experiment}

Change in time in home production

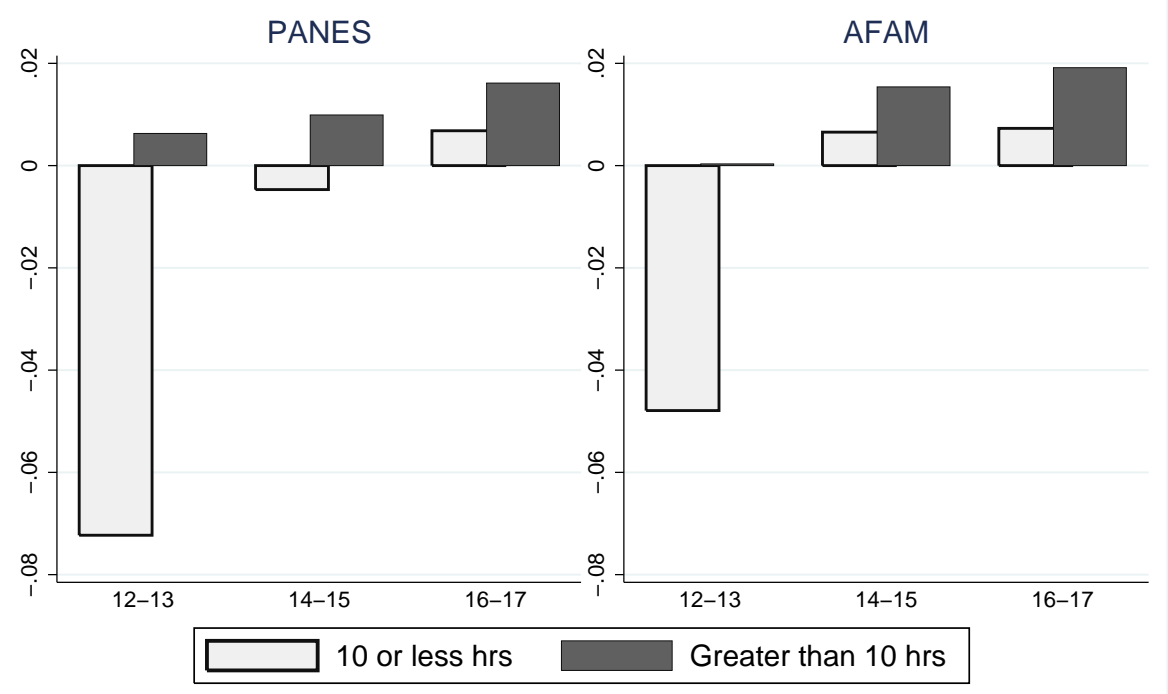

Figure A.2: First Policy Experiment: Differences Between Treated and Control and Policy with a Small Increase of the Enforcement Parameter

\section{First Policy Experiment}

Change in time in market work

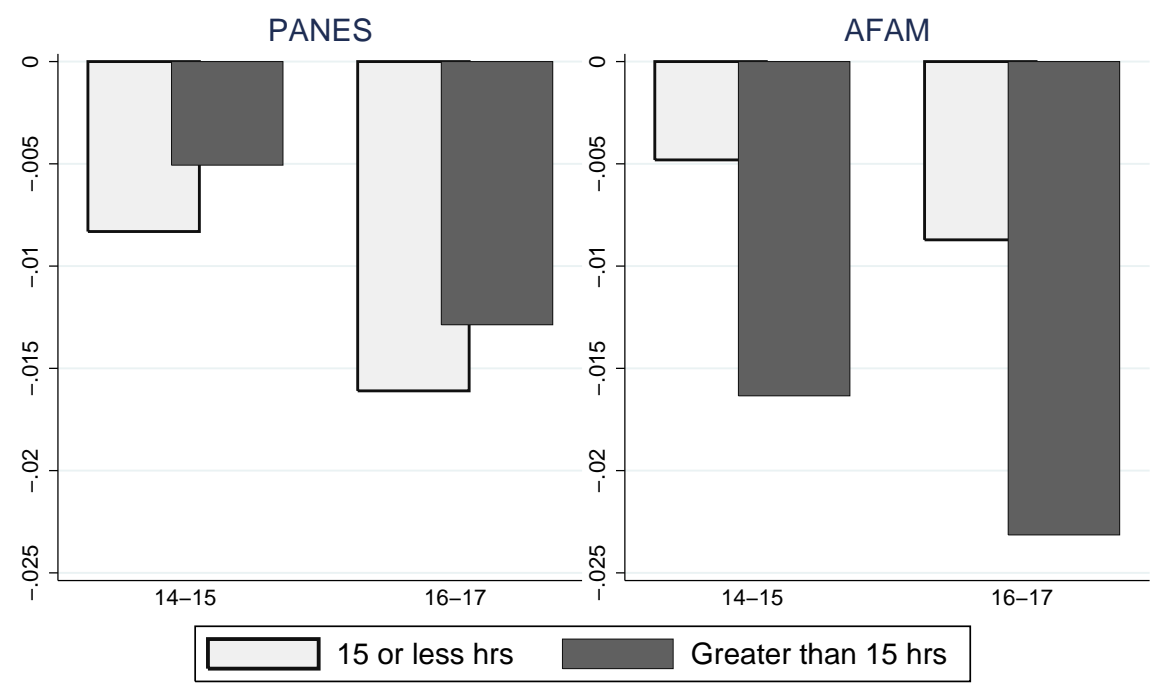


Figure A.3: First Policy Experiment: Differences Between Treated and Control and Policy with a Small Increase of the Enforcement Parameter

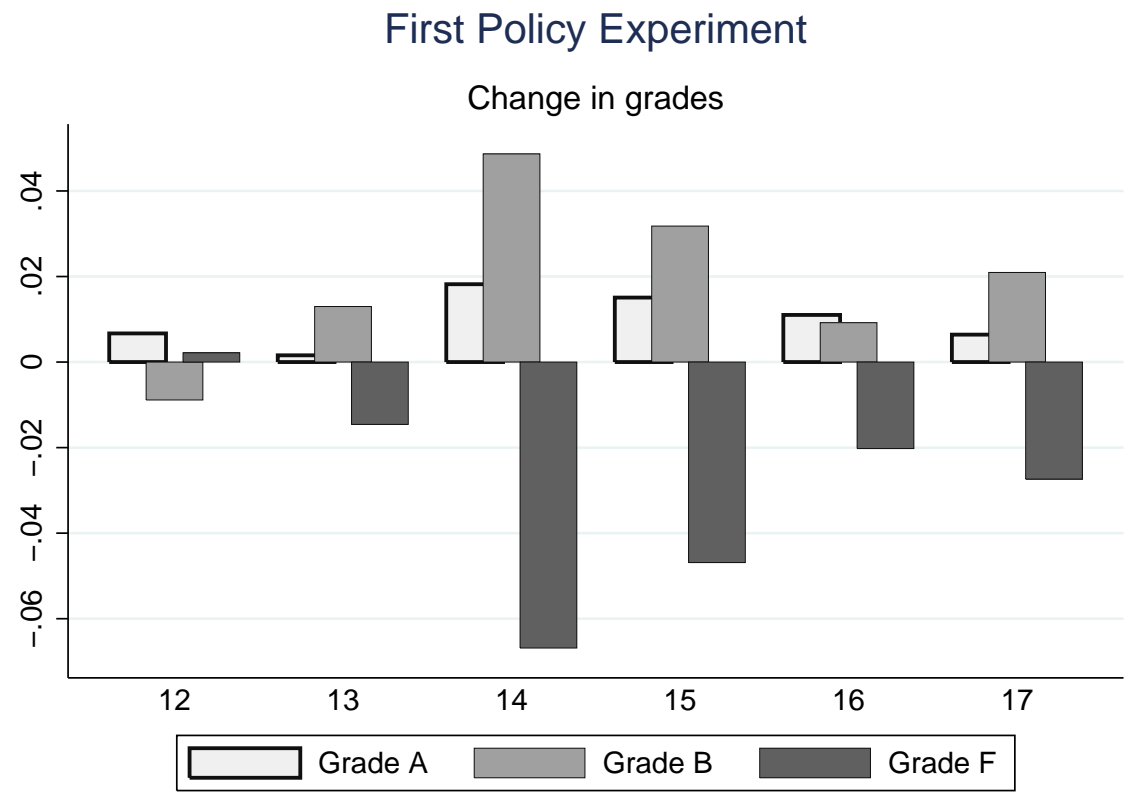

Figure A.4: Second Policy Experiment: Differences Between Treated and Control and Policy with Maximum of the Enforcement Parameter

\section{Second policy experiment}

Change in time in home production

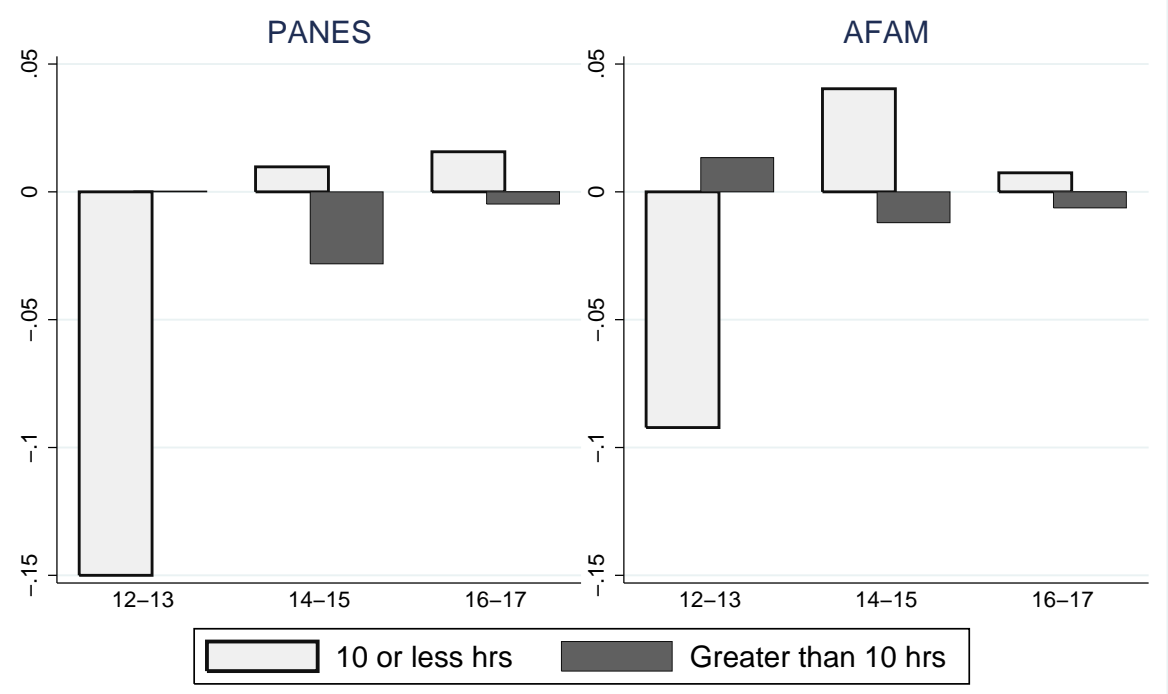


Figure A.5: Second Policy Experiment: Differences Between Treated and Control and Policy with Maximum of the Enforcement Parameter

\section{Second policy experiment}

Change in time in market work

PANES

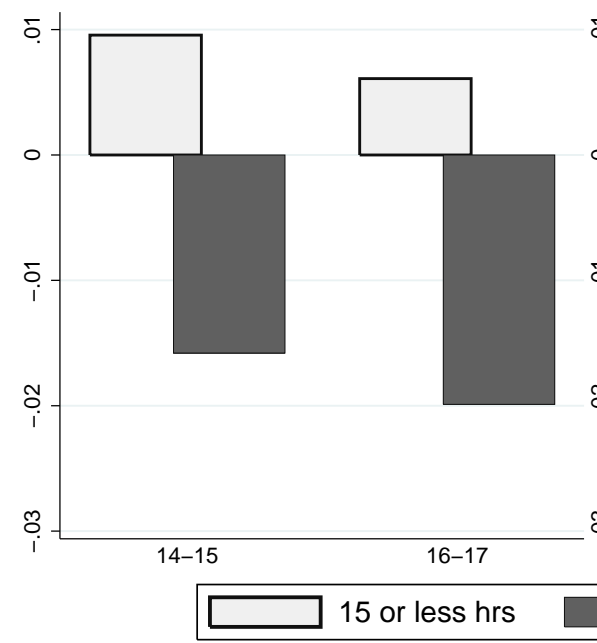

AFAM

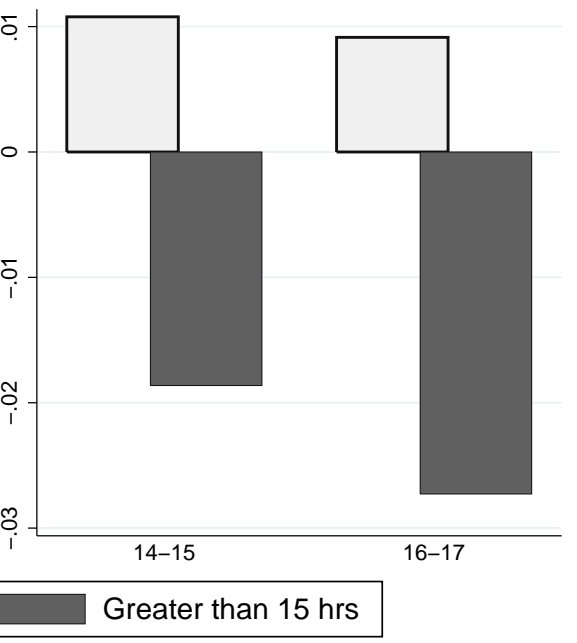

Figure A.6: Second Policy Experiment: Differences Between Treated and Control and Policy with Maximum of the Enforcement Parameter

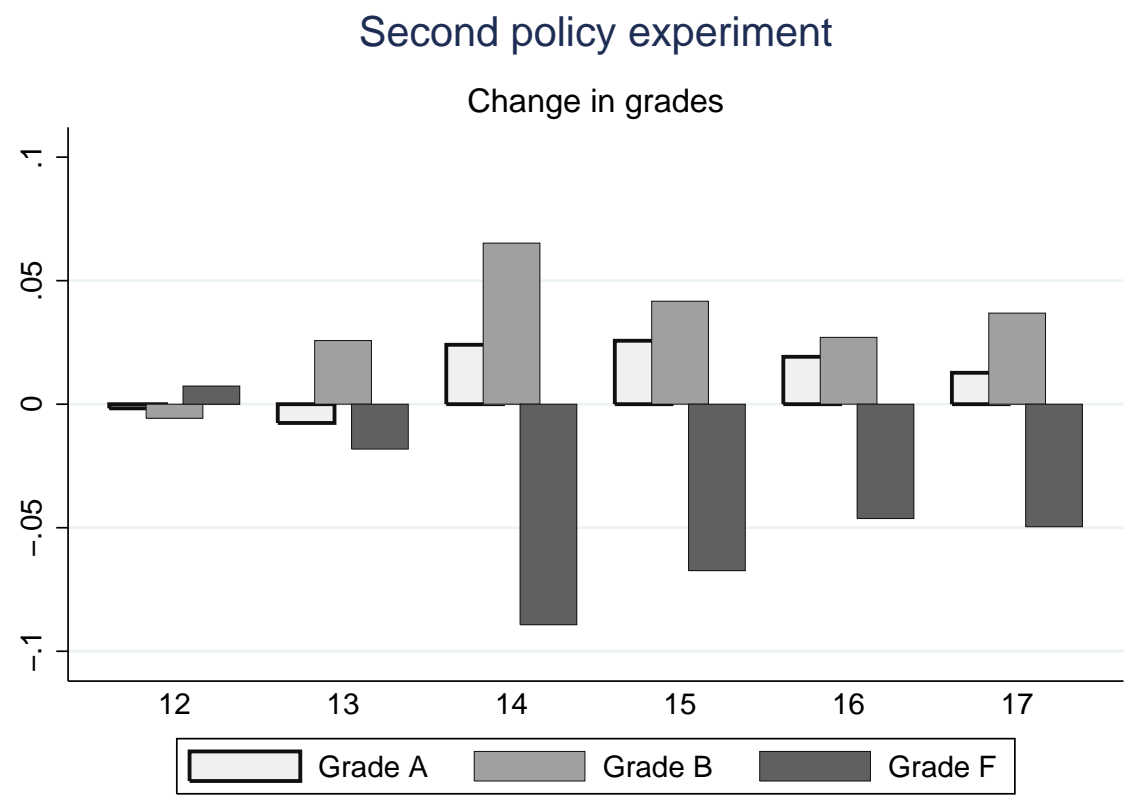


Figure A.7: Third Policy Experiment: Differences Between Treated and Control and Policy of Change Who Receives the Transfer

Third Policy Experiment

Change in time in home production

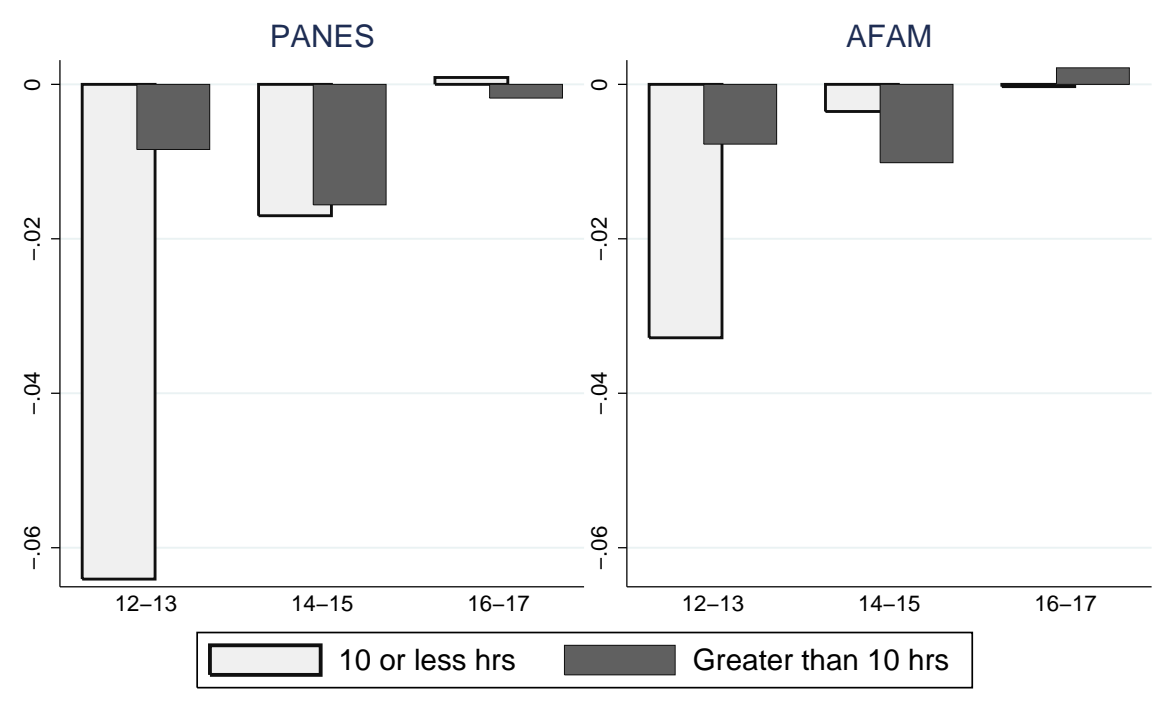

Figure A.8: Third Policy Experiment: Differences Between Treated and Control and Policy of Change Who Receives the Transfer

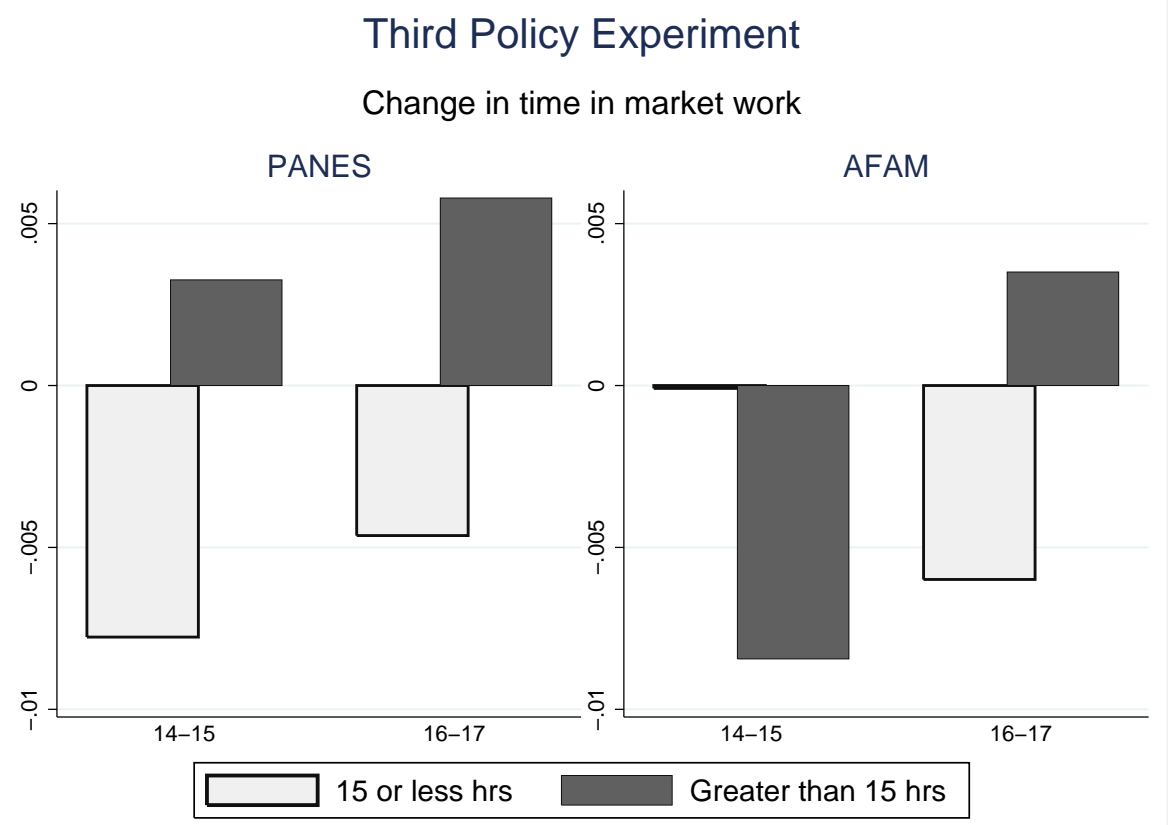


Figure A.9: Third Policy Experiment: Differences Between Treated and Control and Policy of Change Who Receives the Transfer

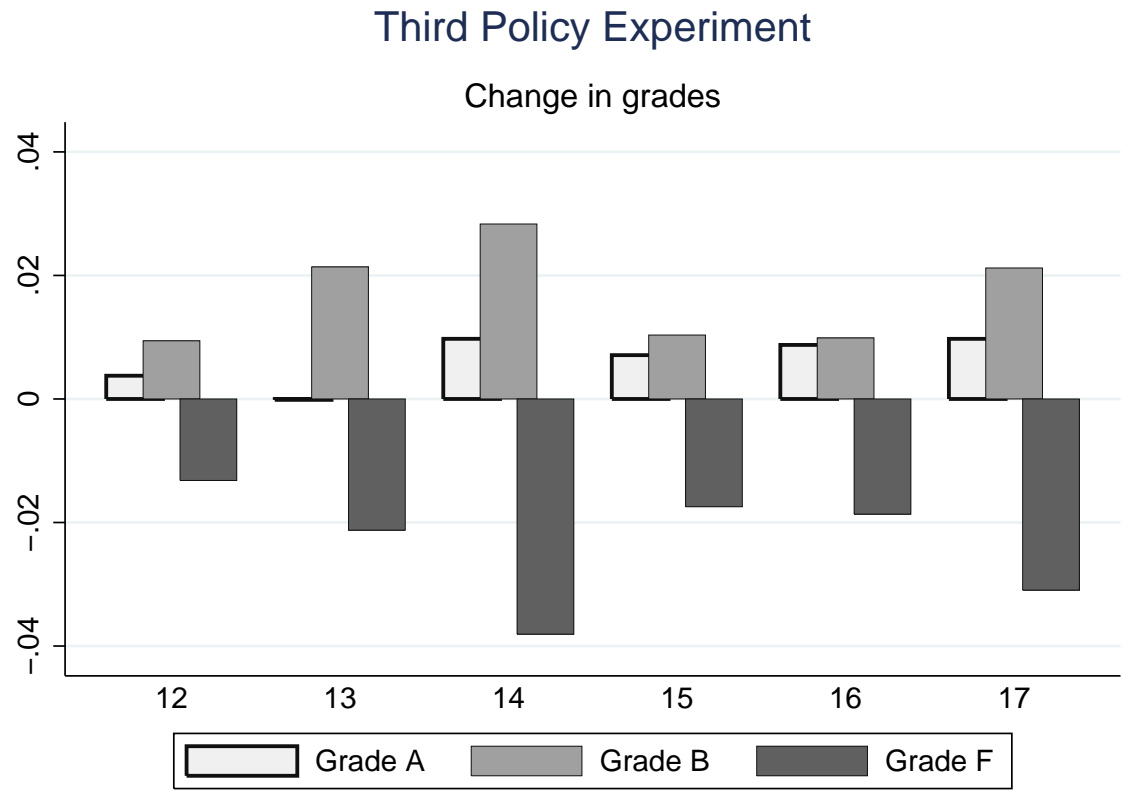

Figure A.10: Fourth Policy Experiment: Differences Between Treated and Control and Policy of Change Who Receives the Transfer and Small Increase the Enforcement Parameter

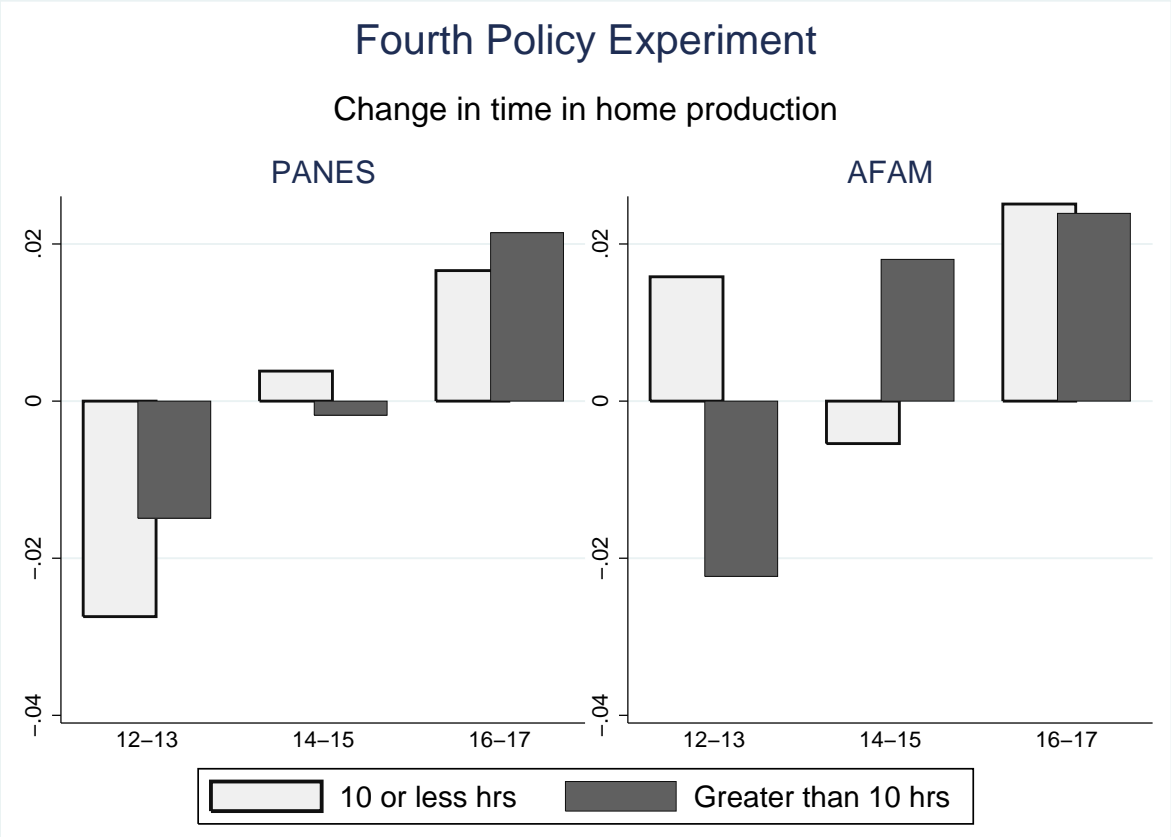


Figure A.11: Fourth Policy Experiment: Differences Between Treated and Control and Policy of Change Who Receives the Transfer and Small Increase the Enforcement Parameter

\section{Fourth Policy Experiment}

Change in time in market work

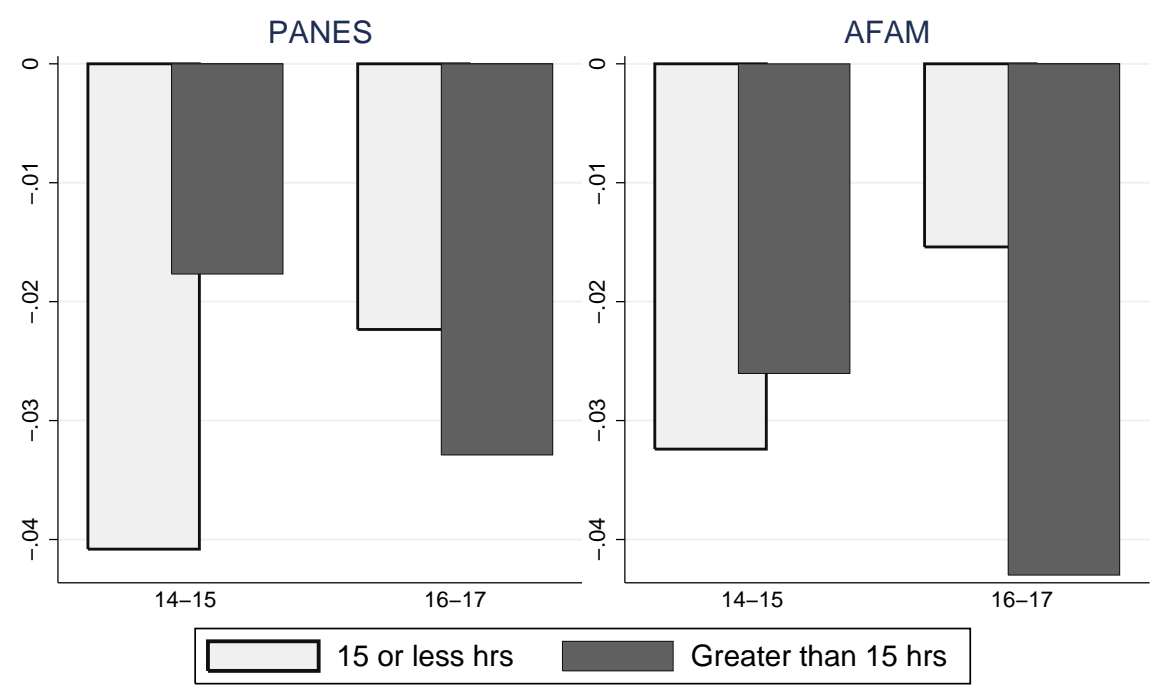

Figure A.12: Fourth Policy Experiment: Differences Between Treated and Control and Policy of Change Who Receives the Transfer and Small Increase the Enforcement Parameter

\section{Fourth Policy Experiment}

Change in grades

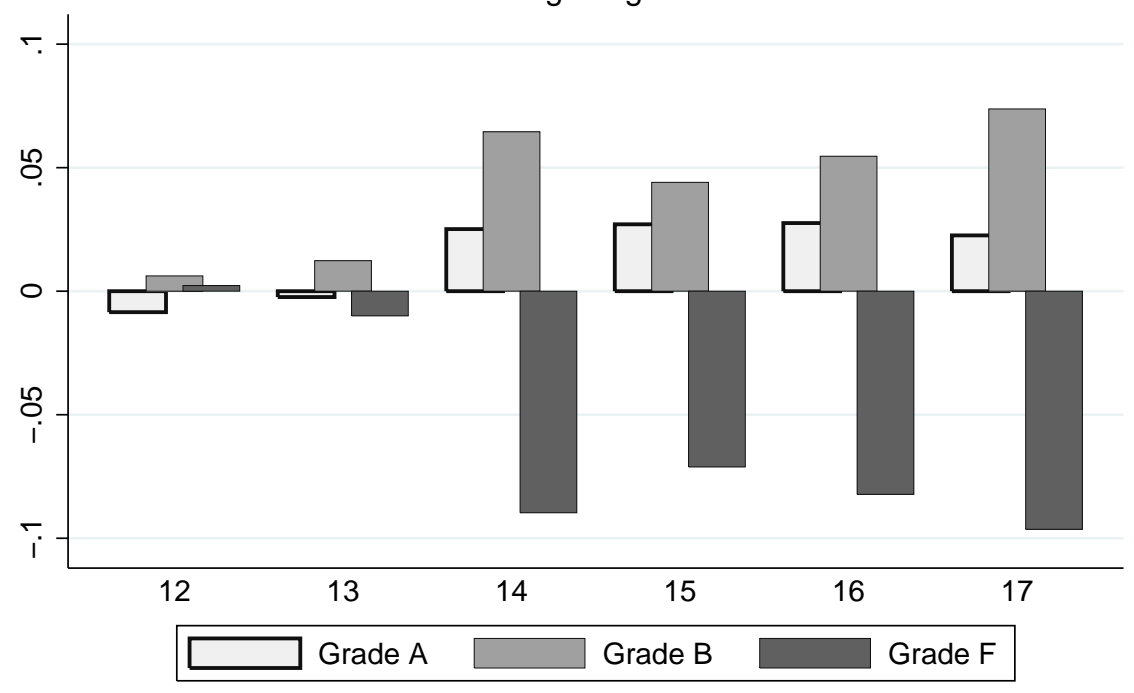


Figure A.13: Fifth Policy Experiment: Differences Between Treated and Control and Policy of Change Who Receives the Transfer and Maximum Enforcement Parameter

\section{Fifth Policy Experiment}

Change in time in home production

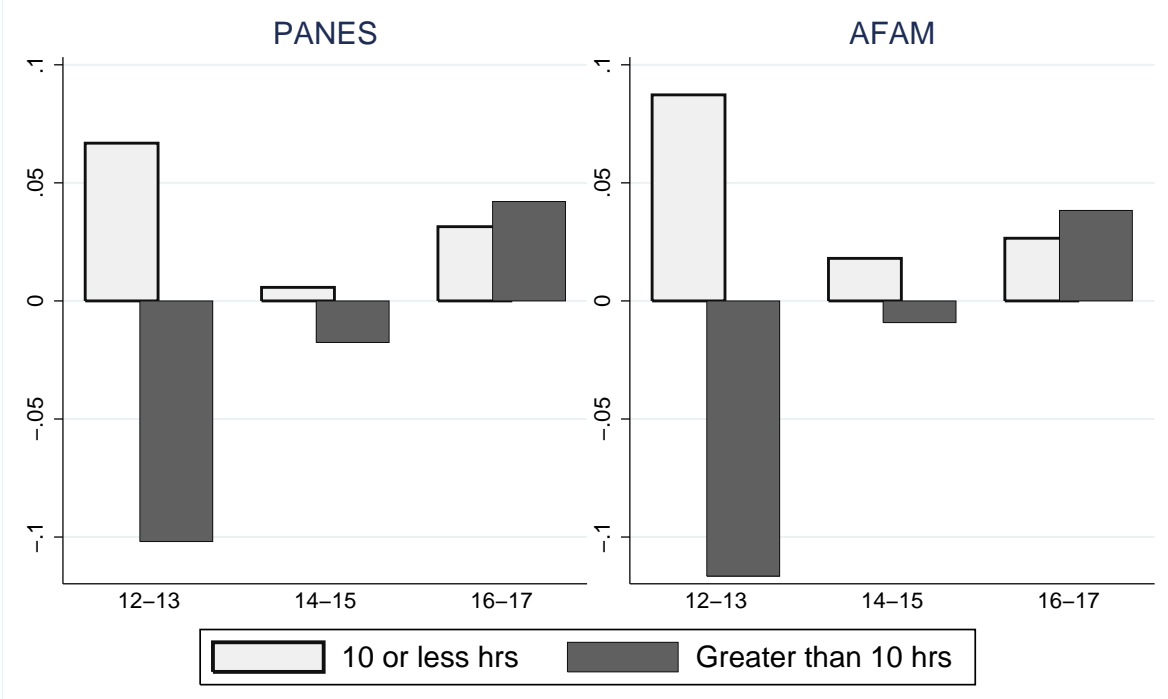

Figure A.14: Fifth Policy Experiment: Differences Between Treated and Control and Policy of Change Who Receives the Transfer and Maximum Enforcement Parameter

\section{Fifth Policy Experiment}

Change in time in market work

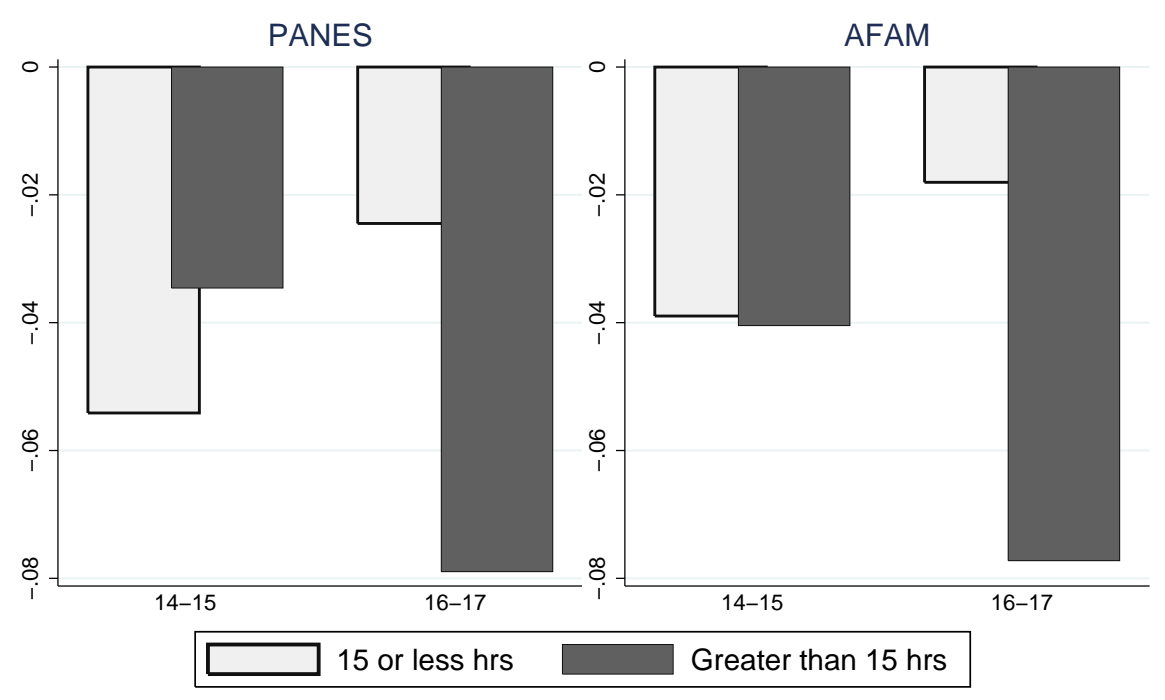


Figure A.15: Fifth Policy Experiment: Differences Between Treated and Control and Policy of Change Who Receives the Transfer and Maximum Enforcement Parameter

Fifth Policy Experiment

\section{Change in grades}

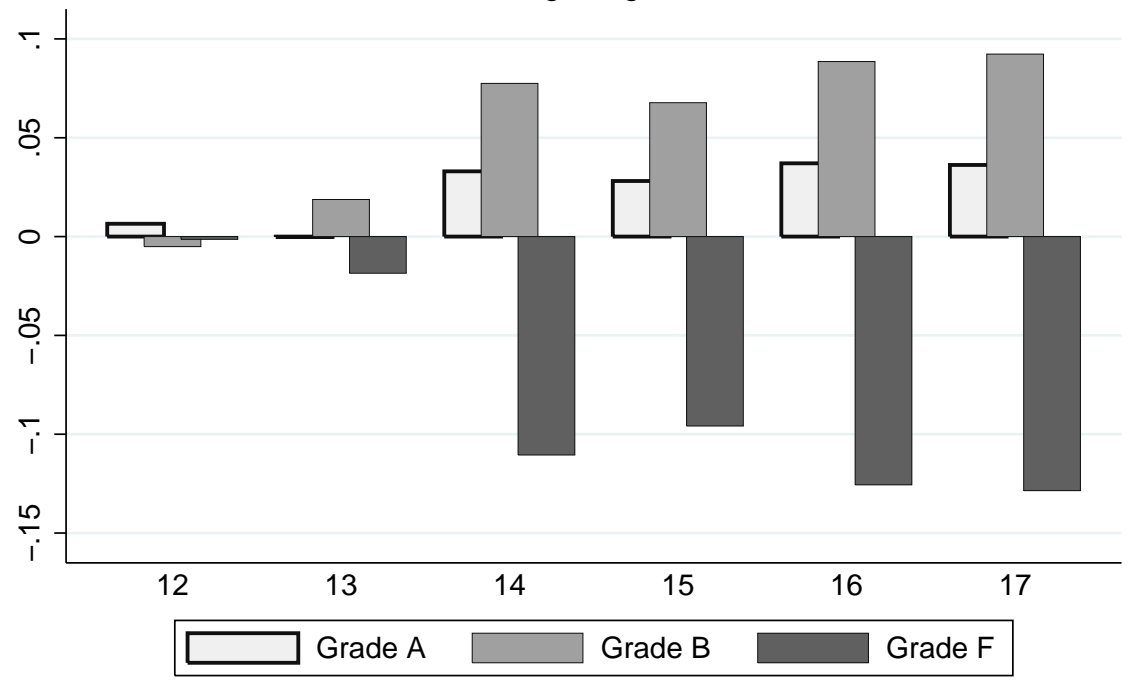




\section{INSTITUTO DE ECONOMÍA}

\section{Serie Documentos de Trabajo}

Julio, 2019

DT 17/2019

\section{iecon}

Instituto de Economía

Facultad de Ciencias Económicas y de Administración

Universidad de la República - Uruguay

(C) 2011 iecon.ccee.edu.uy | instituto@iecon.ccee.edu.uy | Tel: +598 24000466 | Gonzalo Ramírez 1926 | C.P. 11200 | Montevideo - Uruguay 